NBER WORKING PAPER SERIES

\title{
IMPLICATIONS OF INCREASING COLLEGE ATTAINMENT FOR AGING IN GENERAL EQUILIBRIUM
}

\author{
Juan Carlos Conesa \\ Timothy J. Kehoe \\ Vegard M. Nygaard \\ Gajendran Raveendranathan \\ Working Paper 26000 \\ http://www.nber.org/papers/w26000 \\ NATIONAL BUREAU OF ECONOMIC RESEARCH \\ 1050 Massachusetts Avenue \\ Cambridge, MA 02138 \\ June 2019, Revised January 2020
}

This project was supported by the National Institutes of Health (NIH Grant No. 5R01AG048037-02). We thank Daniela Costa, Parisa Kamali, and Akshar Saxena for their help during an early stage of the paper. We thank seminar participants at the Barcelona GSE Summer Forum, the Bellaterra Macroeconomics Winter Workshop, the Institute for Fiscal Studies, McMaster University, the NBER Summer Institute, SAEe, Santa Barbara, SED, and Universidad Torcuto di Tella for helpful discussions and suggestions. The views expressed herein are those of the authors and not necessarily those of the Federal Reserve Bank of Minneapolis, the Federal Reserve System, or the National Bureau of Economic Research.

NBER working papers are circulated for discussion and comment purposes. They have not been peer-reviewed or been subject to the review by the NBER Board of Directors that accompanies official NBER publications.

(C) 2019 by Juan Carlos Conesa, Timothy J. Kehoe, Vegard M. Nygaard, and Gajendran Raveendranathan. All rights reserved. Short sections of text, not to exceed two paragraphs, may be quoted without explicit permission provided that full credit, including $\odot$ notice, is given to the source. 
Implications of Increasing College Attainment for Aging in General Equilibrium

Juan Carlos Conesa, Timothy J. Kehoe, Vegard M. Nygaard, and Gajendran Raveendranathan

NBER Working Paper No. 26000

June 2019, Revised January 2020

JEL No. H20,H51,H55,I13,J11

\section{ABSTRACT}

We develop an overlapping generations general equilibrium model of the U.S. economy with heterogeneous consumers who face idiosyncratic earnings and health risk to study the implications of increasing college attainment, decreasing fertility, and increasing longevity (2005-2100). While all three trends contribute to a higher old age dependency ratio, increasing college attainment has different implications because it increases labor productivity. Decreasing fertility and increasing longevity require the government to increase the average labor tax rate from 33.5 to 47.1 percent. Increasing college attainment lowers the required tax increase by 12.0 percentage points. The labor tax rate required to balance the government budget is higher under general equilibrium than in a small open economy with a constant interest rate, because the reduction in the interest rate lowers capital income tax revenues.

\author{
Juan Carlos Conesa \\ Department of Economics \\ Stony Brook University \\ Stony Brook, NY 11794-4384 \\ juan.conesa@stonybrook.edu \\ Timothy J. Kehoe \\ University of Minnesota \\ Department of Economics \\ 1925 Fourth Street South \\ Minneapolis, MN 55455-0462 \\ and Federal Reserve Bank of Minneapolis \\ and also NBER \\ tkehoe@umn.edu
}

Vegard M. Nygaard

Department of Economics

University of Houston

3623 Cullen Boulevard

Houston, TX 77204

United States

vmnygaard@uh.edu

Gajendran Raveendranathan

Department of Economics

MacMaster University

1280 Main Street West

Hamilton Ontario L8S 4M4

Canada

raveeg1@mcmaster.ca 


\section{Introduction}

The ratio of the population 65 and older to the population that is 20 to 64 years old (that is, the old age dependency ratio) in the United States is projected to increase from about 20 percent in 2005 to more than 50 percent by 2100 according to estimates by the United Nations. The literature has used overlapping generations models with heterogeneous consumers to analyze the implications of the projected increase in the old age dependency ratio due to decreasing fertility rates and increasing longevity. Attanasio et al. (2010), for example, have argued that the U.S. government will have to increase the labor tax rate by 12.7 percentage points by 2080 to finance the increase in Medicare, Medicaid, and Social Security spending. Our paper extends this literature by introducing increasing college attainment into the model. We argue that increasing college attainment - which accounts for some of the increase in the old age dependency ratio because collegeeducated individuals have higher life expectancy — has different macroeconomic implications than decreasing fertility and increasing longevity, because higher college attainment leads to a more productive labor force.

Following Conesa et al. (2018), we develop an overlapping generations general equilibrium model with heterogeneous consumers who face idiosyncratic earnings and health risk. Consumers are ex-ante heterogeneous in education. In particular, some are college educated and some are not. Consistent with the data, college-educated consumers in the model have both higher life expectancy and higher labor productivity. Consumers in our model can save in non-state-contingent bonds and partially insure against health risk through employer-provided insurance or by purchasing private insurance. Furthermore, the model incorporates the key social insurance programs in the United States: Medicare; Medicaid; Social Security; and a welfare program that combines institutional features of food stamps, disability insurance, and medical relief for the poor (for brevity, referred to as Emergency Relief). The government finances its spending on consumption, interest payments on debt, Medicare, Medicaid, Emergency Relief, and Social Security by levying consumption taxes, capital income taxes, and labor income taxes. We assume that the consumption and capital income tax rates are fixed and that the government balances its budget each period by adjusting the labor tax rate.

After calibrating the model to match key features of the U.S. economy in 2005, we use the model to study the macroeconomic implications of the three channels that contribute to an increase in the old age dependency ratio mentioned above: increasing college attainment, decreasing fertility, and increasing longevity (for brevity, we refer to the three channels that lead to an increase in the old age dependency ratio as the three channels of aging). In particular, we change the mass of 20-year-olds entering the economy with a college degree, the growth rate of the population of 20-year-olds, and the age-specific survival probabilities to match relevant projections for 2100. Increasing college attainment increases the old age dependency 
ratio because college graduates have higher life expectancy than non-college graduates. Decreasing fertility increases the old age dependency ratio because it leads to relatively fewer young consumers. Lastly, increasing longevity increases the old age dependency ratio because it leads to relatively more older consumers.

We start by studying the individual fiscal implications of the three channels of aging. Our results show that decreasing fertility and increasing longevity require the government to increase the labor tax rate, whereas increasing college attainment allows the government to reduce the labor tax rate. There are a number of reasons for this result. First, and most importantly, an increase in college attainment leads to an economy with more productive workers and therefore higher labor earnings, which in turn leads to higher labor tax revenues. Second, hours worked per capita and labor force participation rates among both workers between the ages of 20 and 64 and those aged 65 and older are higher in the economy with higher college attainment, thereby expanding the labor tax base. Third, college graduates are less likely to enroll in Medicaid and Emergency Relief. Higher college attainment thus reduces government spending on these programs. Fourth, there are general equilibrium effects. Higher college attainment leads to higher capital accumulation, which in turn leads to lower interest rates and higher wages. Lower interest rates reduce interest payments on government debt per capita, thereby lowering government spending. Higher wages lead to a further increase in labor tax revenues, not only because of the direct effect of higher wages on earnings but also because higher wages induce consumers to work more. Finally, higher college attainment leads to higher consumption tax revenues per capita and higher capital income tax revenues per capita. This follows because college graduates both consume and save more than non-college graduates. College graduates save more since they have higher labor earnings, higher life expectancy, and a stronger precautionary savings motive because they are less likely to enroll in Medicaid and Emergency Relief.

The forces that we have mentioned so far contribute to lower labor taxes, but there are forces that move in the opposite direction. In particular, an increase in college attainment leads to higher spending on Medicare and Social Security. This result follows because college-educated consumers have higher life expectancy than non-college-educated consumers and because college-educated consumers claim higher Social Security benefits owing to higher lifetime labor earnings.

We then study the joint fiscal implications of the three channels of aging. In particular, we use the 2100 projections for fertility and longevity but vary the increase in college attainment from 0 to 100 percent of its projected increase. We find that decreasing fertility and increasing longevity require the government to increase the average labor tax rate from 33.5 to 47.1 percent by 2100. Adding increasing college attainment to this model lowers the required increase in the labor tax rate by 12.0 percentage points if college attainment increases to 100 percent of its projected value in 2100. Consequently, we find that all three channels of aging require the government to increase the average labor tax rate from 33.5 to 35.1 percent by 2100 . 
Next, to identify the general equilibrium effects in our results, we compare the results from the benchmark closed economy with those of a small open economy in which the real interest rate is constant and exogenous. By construction, the wage rate in the detrended balanced growth economy is also constant in the small open economy. We find that the capital stock increases in both the general equilibrium model and the small open economy model. In the general equilibrium model, however, the increase in the capital stock also leads to higher wages and lower interest rates. Lower interest rates reduce government revenues from capital income taxation. Consequently, we find that the three channels of aging reduce capital income tax revenues per capita by 13.1 percent in the general equilibrium model but increase capital income tax revenues per capita by 89.4 percent in the small open economy model. As a result, we find that the labor tax rate required to balance the government budget is higher under general equilibrium. Whereas higher college attainment lowers the required increase in the labor tax rate due to decreased fertility and increased longevity by 12.0 percentage points under general equilibrium, we find that the three channels of aging allows the government to reduce the labor tax rate by 6.0 percentage points in the small open economy model.

Finally, we study the welfare implications of increasing college attainment. To do this, we first compute two demographic transitions: one where we introduce all three channels of aging, and another where we only decrease fertility and increase longevity. We then quantify the welfare implications of increasing college attainment by comparing the welfare results between these two demographic transitions. We start by studying the welfare implications for consumers under the veil of ignorance. By "veil of ignorance", we mean that we focus on 20-year-old consumers with zero assets for whom the education type (college or non-college), but not the stochastic components of productivity and health, has been revealed. We report the welfare results from the productivity-detrended models. We find that non-college-educated consumers who enter the transition with decreasing fertility and increasing longevity in 2010 require a one-time transfer equal to 2.0 percent of GDP per capita to be indifferent between the two transitions. The corresponding transfer for college-educated consumers is 0.6 percent of GDP per capita. Hence, higher college attainment leads to welfare gains for consumers under the veil of ignorance. Moreover, these welfare gains are increasing over the transition. Accordingly, we find that non-college graduates who enter the transition with decreasing fertility and increasing longevity in 2100 require a transfer of 160.0 percent of GDP per capita to be indifferent between the two transitions, whereas a transfer of 18.1 percent of GDP per capita is required to equalize welfare for college-educated consumers. Lastly, we study the welfare implications for the current cohort. We find that higher college attainment increases average welfare of the current cohort but that the welfare gains are heterogeneous across both age groups and educational types. In particular, we find that 25-yearold college graduates in the transition with decreasing fertility and increasing longevity require a one-time transfer of 4.6 percent of GDP per capita to be indifferent between that transition and the transition with 
all three channels of aging. The corresponding transfer for 25-year-old non-college graduates is 2.8 percent of GDP per capita. Similarly, we find that the current old consumers generally benefit from higher college attainment but that their welfare gains are smaller compared to the younger population.

Our paper is related to the literature that develops general equilibrium overlapping generations models to study the implications of decreasing fertility and increasing longevity. These demographic trends will lead to a large increase in government spending on Medicare, Medicaid, and Social Security over the next century. De Nardi et al. (1999), Kotlikoff et al. (2007), and Attanasio et al. (2010) study the macroeconomic and welfare implications of various fiscal policy reforms that have been proposed to finance government spending on social insurance programs in the future, such as increasing payroll taxes, increasing the eligibility age for benefits, or reducing the generosity of benefits. In a recent paper, Jung et al. (2017) develop a general equilibrium overlapping generations model with endogenous health to study the implications of aging for health care spending and health insurance coverage. They use the model to study how the implications of aging are affected by the introduction of the Patient Protection and Affordable Care Act (ACA). Unlike our paper, these papers do not focus on increasing college attainment. While increasing college attainment, decreasing fertility, and increasing longevity all contribute to an increase in the old age dependency ratio, we show that increasing college attainment has different fiscal and welfare implications than decreasing fertility and increasing longevity, because increasing college attainment leads to a more productive labor force.

The model we use in the paper builds on the model used by Conesa and Krueger (1999) to study Social Security reforms and the models used by Pashchenko and Porapakkarm (2013) and Jung and Tran (2016) to examine the implications of the ACA. It also builds on the model used by Hubbard et al. (1994), Palumbo (1999), De Nardi et al. (2010), and Kopecky and Koreshkova (2014) to examine how medical expenditure risk affects the savings of the elderly. The model is most closely related to the model in Conesa et al (2018). The main difference between the model in this paper and the model in Conesa et al. (2018) is in how we model the fiscal system. Whereas Conesa et al. (2018) allow only for labor taxes, the present model includes capital, consumption, and labor taxes. Moreover, we include government consumption, government debt, and taxes on Social Security benefits. We also consider an alternative tax system where we allow for progressive income taxes as part of our sensitivity analysis.

The rest of the paper is organized as follows. Section 2 presents the benchmark model used in the paper. After calibrating the model in Section 3, we study the fiscal and welfare implications of increasing college attainment, decreasing fertility, and increasing longevity in Section 4. Lastly, Section 5 concludes and gives directions for future research. 


\section{Model}

The following subsections present the benchmark model used in the analysis. The model is a discrete time, general equilibrium overlapping generations model with heterogeneous consumers. As noted earlier, the model builds on that in Conesa et al. (2018).

\section{$2.1 \quad$ Firms}

Firms hire labor at wage $w_{t}$ and rent capital at rate $r_{t}$ from consumers to produce goods. We assume that the technology at time $t$ can be represented by a constant returns to scale Cobb-Douglas production function:

$$
\hat{Y}_{t}=\hat{K}_{t}^{\alpha}\left(Z_{t} N_{t}\right)^{1-\alpha}
$$

where $\hat{K}_{t}$ is the aggregate capital stock, $Z_{t}$ denotes labor-augmenting technological progress, $N_{t}$ denotes effective labor supply, and $\alpha$ is capital's share of income. Technological progress is given by $Z_{t}=\theta\left(1+g_{z}\right)^{t}$, where $g_{z}$ denotes the growth rate of technology. Similarly, $g_{n}$ denotes the growth rate of 20-year-old consumers, which is the age at which consumers enter the economy.

Output is used for private consumption, $\hat{C}_{t}$; government consumption, $\hat{G}_{c, t}$; investment, $\hat{K}_{t+1}-(1-\delta) \hat{K}_{t}$;

and purchase of health care services, $\hat{M}_{t}$, where $\delta$ denotes the rate of capital depreciation. Let $x_{t} \equiv \frac{\hat{x}_{t}}{\left(1+g_{z}\right)^{t}}$ denote productivity-detrended variables. The productivity- and population-growth detrended resource constraint in the balanced growth path is

$$
C_{t}+G_{c, t}+M_{t}+\left(1+g_{z}\right)\left(1+g_{n}\right) K_{t+1}=K_{t}^{\alpha}\left(\theta N_{t}\right)^{1-\alpha}+(1-\delta) K_{t} .
$$

For the remainder of the paper, we drop time subscripts and use $/$ to denote next-period variables.

\subsection{Consumers}

The economy is populated by a continuum of ex-ante and ex-post heterogeneous consumers. Consumers are indexed by type $s=(j, e, h, \eta, a, i)$, where $j$ is age, $e$ is educational level, $h$ is health status, $\eta$ is the stochastic component of labor productivity, $a$ is assets, and $i$ is the consumer's health insurance status. We let $\Phi(s)$ denote the measure of consumers of type $s$.

The consumer's educational level is permanent over her lifetime and can take two values: college or noncollege. Health status is stochastic and is a function of the consumer's current age, education, and health. 
It follows a finite-state Markov process with stationary transitions over time:

$$
Q_{j, e}(h, H)=\operatorname{Prob}\left(h^{\prime} \in H:(h, j, e)\right),
$$

where $Q_{j, e}(h, H)$ denotes the probability of the next period's health conditional on current health, age, and education. The stochastic component of labor productivity is given by a stationary finite-state Markov process:

$$
Q(\eta, E)=\operatorname{Prob}\left(\eta^{\prime} \in E: \eta\right)
$$

where $Q(\eta, E)$ denotes the probability of next period's stochastic labor productivity conditional on current stochastic labor productivity. Lastly, the consumer's health insurance status, $i$, specifies whether she is uninsured, $i_{S}$; has private health insurance, $i_{P}$; or has employer-provided health insurance, $i_{E}$.

Consumers are endowed with one unit of time in every period that can be allocated between work and leisure. The period-by-period utility function is given by

$$
U\left(c, \ell, e, i_{C A I D}\right)=\frac{\left[c^{\gamma}\left(1-\ell-f_{e}\right)^{1-\gamma}\right]^{1-\sigma}}{1-\sigma}-\mathbb{I}_{i_{C A I D}=1} \kappa
$$

where $c$ denotes consumption and $\ell$ denotes labor supply. We assume that labor supply is indivisible, $\ell \in\left\{0, \ell_{p}, \ldots, \ell_{e}\right\}$, where $\ell_{p}$ and $\ell_{e}$ refer to part-time and extra time, respectively. We capture some of the costs of going to college by means of a time cost, $f_{e}$. In particular, we assume that consumers with a college degree spend part of their first 4 years in college. Their total time endowment available for work and leisure in the first 4 years is thus given by $1-f_{e}$. Consumers that qualify for Medicaid in the model choose whether to enroll in the program, $i_{C A I D} \in\{0,1\}$. Eligible consumers that choose to enroll suffer a utility cost, $\kappa$. This utility cost enables us to account for the observation that a large percentage of individuals that qualify for Medicaid in the United States do not enroll in the program. The consumer's labor earnings depend on her labor supply, $\ell$; stochastic labor productivity, $\eta$; health status, $\xi_{h}$; and deterministic life cycle labor productivity, $\epsilon_{j e}$, the last of which varies with the consumer's age and educational level. Starting at age $j_{r}$, all consumers receive health insurance from the government in the form of Medicare. They also receive Social Security benefits, $S S_{j e}$, which depend on their cohort and education. Lastly, consumers face a conditional survival probability, $\psi_{j e h}$, which depends on their age, education, and health. The maximum life span of consumers is $J$. In the event of death, the consumers's assets are distributed across the population. We assume that these accidental bequests, $B_{j}$, are uniformly distributed across 50 - to 60 -year-olds in the model. 


\subsection{Health insurance and welfare programs}

This section presents the different types of health insurance in the economy. As noted earlier, health insurance is available in the form of private health insurance and employer-provided health insurance. In addition, the government provides health insurance through Medicare and Medicaid. Health insurance is used to cover non-discretionary health care expenses, $m_{j h}$, which vary with the consumer's age and health status. Throughout, we let $\chi_{P}, \chi_{E}, \chi_{C A R E}$, and $\chi_{C A I D}$ denote the coinsurance rate for private health insurance, employer-provided health insurance, Medicare, and Medicaid, respectively. To illustrate, a value of 0.229 for $\chi_{P}$ means that the consumer covers 22.9 percent of the health care expenses, and that private health insurance covers the remaining 77.1 percent of the health care expenses.

Medicaid Medicaid is a means-tested program that provides health insurance to income- and asset-poor consumers. Consistent with the U.S. eligibility criteria, we model two ways to qualify for Medicaid. First, consumers qualify under the categorical criterion if the sum of their gross income and interest earnings is below a threshold, $y^{C A T}$. Second, consumers qualify under the medically needy criterion if the sum of their gross income and interest earnings net of out-of-pocket medical expenses is below a threshold, $y^{M N}$, and their assets are less than a threshold, $a^{M N}$. As noted earlier, consumers who qualify for Medicaid in the model choose whether to enroll in the program. Eligible consumers that choose to enroll, $i_{C A I D}=1$, suffer a utility cost $\kappa$.

Medicare The government also provides health insurance in the form of Medicare. Unlike Medicaid, Medicare is not a means-tested program, but covers a share $1-\chi_{C A R E}$ of health care expenses of all consumers aged $j_{r}$ and older. Since Medicare has a positive coinsurance rate, $\chi_{C A R E}>0$, old consumers can purchase private health insurance to further lower their out-of-pocket medical expenditure risk.

Emergency relief The government runs a welfare program that combines institutional features of food stamps, disability insurance, and medical relief for the poor (for brevity, referred to as Emergency Relief). To qualify for this program in the model, consumers have to forfeit all assets and work zero hours. In return, the government covers all health care costs and guarantees a minimum consumption level, $\underline{c}$. We assume that consumers who choose to go on Emergency Relief suffer the same utility cost as those who enroll in Medicaid, $\kappa$.

Private health insurance Consumers can purchase private health insurance for the following period. We assume that the premium for private health insurance is actuarially fair for each insurance pool, where 
the insurance pool is given by consumers with the same age, education, and health $(j, e, h)$. This gives the following expression for the detrended private health insurance premium:

$$
\pi_{j e h}=\left\{\begin{array}{cc}
\frac{\psi_{j e h}\left(1-\chi_{P}\right)\left(1+g_{z}\right) \int m_{j^{\prime} h^{\prime}} Q_{j, e}\left(h, d h^{\prime}\right)}{1+r} & \text { if } j<j_{r}-1 \\
\frac{\psi_{j e h}\left(1-\chi_{P}\right) \chi_{C A R E}\left(1+g_{z}\right) \int m_{j^{\prime} h^{\prime}} Q_{j, e}\left(h, d h^{\prime}\right)}{1+r} & \text { if } j \geq j_{r}-1,
\end{array}\right.
$$

where $\pi_{j e h}$ is the expected medical expense for the insurance company, discounted by the interest rate.

Employer-provided health insurance We assume that a fraction of consumers who are younger than age $j_{r}$ work for an employer that provides health insurance. In that case, $i=i_{E}$. The employer pools the health care expenses of all their employees who do not choose to go on Emergency Relief. These costs are then split evenly across the employees. That is, we model employer-provided health insurance as a pay-asyou-go system where current contributors pay for the health care expenses of current receivers. This gives the following expression for the detrended employer-provided health insurance premium:

$$
\pi_{E}=\frac{\left(1-\chi_{E}\right) \int \mathbf{1}_{F=0} m_{j h} \Phi\left(\left\{1, \ldots, j_{r}-1\right\} \times d e \times d h \times d \eta \times d a \times\left\{i_{E}\right\}\right)}{\int \mathbf{1}_{\ell>0} \Phi\left(\left\{1, \ldots, j_{r}-1\right\} \times d e \times d h \times d \eta \times d a \times\left\{i_{E}\right\}\right)}
$$

where the indicator function $\mathbf{1}_{F=0}$ in the numerator equals one for all consumers who do not choose to go on Emergency Relief. We assume that consumers are not allowed to have both employer-provided and private health insurance. Moreover, to alleviate the adverse selection problem associated with group insurance plans, we assume that consumers who work for an employer that provides health insurance are not allowed to opt out of employer-provided insurance. Lastly, motivated by the low take-up rate of employer-provided health insurance among individuals who are older than 65 in the United States, we assume that consumers aged $j_{r}$ and older do not receive employer-provided insurance in the model.

\subsection{Government}

The government is engaged in five activities in the model. First, as already noted, it provides public health insurance in the form of Medicare and Medicaid. Second, it runs a welfare program that covers all health care costs and guarantees a minimum consumption level. Third, it consumes goods. We assume that government consumption per capita, $\hat{g}_{c}$, grows at the rate of technological progress. Hence, total government consumption is given by $\hat{G}_{c}=\hat{g}_{c} \int \Phi(d s)$. We include government consumption in the model to equalize the size of the government sector in the model and the data, thereby ensuring that the tax burden in the model 
is consistent with the data. Fourth, it supplies one-period risk-free debt, $\hat{D}$, which by no arbitrage carries the same return as physical capital in equilibrium. We assume that government debt grows at the rate of technological progress. Lastly, it runs a Social Security program. In the United States, Social Security payments are tied to an individual's earnings history. To reduce computational costs, we abstract from this in the model and assume that benefits depend only on the consumer's education and cohort. In particular, we assume that a cohort's Social Security benefits depend on the wage rates that existed in the economy during the last 35 years before that cohort reached retirement age. Let $b_{e}$ denote the education-specific Social Security replacement rate. Detrended Social Security benefits are given by

$$
S S_{e j}=\frac{b_{e}}{35} \sum_{k=j_{r}-35}^{j_{r}-1} \frac{w_{k-j}}{\left(1+g_{z}\right)^{j-k}} .
$$

This functional form implies that younger cohorts will receive higher Social Security benefits than older cohorts because of productivity-induced wage growth. Note that the dependence on education enables us to partially account for the fact that college-educated consumers claim higher Social Security benefits due to higher lifetime labor earnings.

The government finances its expenditures on consumption, interest payments on debt, Medicare, Medicaid, Emergency Relief, and Social Security by means of three taxes: a consumption tax, $\tau_{c}$; a capital income tax on the net return on wealth, $\tau_{k}$; and a proportional labor tax, $\tau_{\ell}$. Let $G_{M}$ denote total productivitydetrended government spending on Medicare, Medicaid, and Emergency Relief. We assume that consumers on Emergency Relief do not pay taxes on their consumption. Moreover, we assume that the consumption and capital income tax rates stay fixed and that the government balances its budget every period by means of the labor tax. The labor tax rate then has to satisfy

$$
\begin{gathered}
\tau_{\ell} w N+\tau_{c} \int \mathbf{1}_{F=0} c(s) \Phi(d s)+\tau_{k} r \int\left(a(s)+B_{j}\right) \Phi(d s)+\left(1+g_{z}\right)\left(1+g_{n}\right) D^{\prime} \\
=G_{M}+g_{c} \int \Phi(d s)+(1+r) D+S S_{e j} \int \Phi\left(d s \mid j \geq j_{r}\right)
\end{gathered}
$$

where the indicator function $\mathbf{1}_{F=0}$ equals one for all consumers who do not choose to go on Emergency Relief, and where by $\Phi\left(d s \mid j \geq j_{r}\right)=\Phi\left(\left\{j_{r}, \ldots, J\right\} \times d e \times d h \times d \eta \times d a \times d i\right)$ it is understood that the integral is over all types $s$ but restricted to agents of age $j \geq j_{r}$.

\subsection{Consumer problem}

The consumer's choice set depends on her current age and health insurance status. Throughout, we use the word young to denote consumers less than age $j_{r}$ and old to denote consumers that are at least $j_{r}$ years old. We start by presenting the problem of young consumers with private health insurance. This subsection also 
defines the value of going on Emergency Relief. Next, we set up the problem faced by young consumers with employer-provided health insurance. Lastly, we discuss the problem of old consumers.

\subsubsection{Young consumers without employer-provided health insurance}

Recall that a consumer's type is given by $s=(j, e, h, \eta, a, i)$, where $j$ is age, $e$ is educational level, $h$ is health status, $\eta$ is the stochastic component of labor productivity, $a$ is assets, and $i$ is the consumer's health insurance status. Let $V^{N E}(s)$ denote the value of young consumers without employer-provided health insurance. Similarly, let $V^{F}(s)$ denote the value of going on Emergency Relief. Young consumers without employer insurance then solve the following problem:

$$
V(s)=\max \left\{V^{N E}(s), V^{F}(s)\right\}
$$

where $V^{N E}(s)$ is given by

$$
\begin{aligned}
V^{N E}(s)= & \max _{c, a^{\prime}, \ell i^{\prime}, i_{C A I D}} U\left(c, \ell, e, i_{C A I D}\right)+\beta \psi_{j e h} \mathbb{E}_{\eta^{\prime} \mid \eta} \mathbb{E}_{h^{\prime} \mid j e h} V\left(s^{\prime}\right) \\
\text { s.t. } & \left(1+\tau_{c}\right) c+\left(1+g_{z}\right) a^{\prime}+m_{o p}+\mathbf{1}_{i^{\prime}=i_{P}} \pi_{j e h}=w\left(1-\tau_{\ell}\right) \eta \xi_{h} \epsilon_{j e} \ell+\left(1+r\left(1-\tau_{k}\right)\right)\left(a+B_{j}\right) \\
& m_{o p}= \begin{cases}\mathbf{1}_{i=i_{P}} \chi_{P} m_{j h}+\left(1-\mathbf{1}_{i=i_{P}}\right) m_{j h} & \text { if } \mathbf{1}_{C A I D}(s, \ell)=0 \\
\mathbf{1}_{i=i_{P}} \chi_{P} \chi_{C A I D} m_{j h}+\left(1-\mathbf{1}_{i=i_{P}}\right) \chi_{C A I D} m_{j h} & \text { if } \mathbf{1}_{C A I D}(s, \ell)=1 \\
& \ell \in\left\{0, \ell_{p}, \ldots, \ell_{e}\right\} \\
& c, a^{\prime} \geq 0 \\
& i^{\prime} \in\left\{i_{P}, i_{S}\right\} \\
& i_{C A I D} \in\{0,1\} .\end{cases}
\end{aligned}
$$

Consumers without employer-provided insurance choose how much to consume, $c$; how much to save, $a^{\prime}$; how many hours to work, $\ell$; and whether to purchase private health insurance for the following period, $i^{\prime}$. In addition, consumers who qualify for Medicaid, $\mathbf{1}_{C A I D}(s, \ell)=1$, choose whether to enroll in the program, $i_{C A I D}$. As noted earlier, eligible consumers who choose to enroll, $i_{C A I D}=1$, suffer a utility cost, $\kappa$. In the event that a qualified consumer chooses to enroll in Medicaid, Medicaid will cover a share $1-\chi_{C A I D}$ of the consumer's out-of-pocket medical expenses, $m_{o p}$, which are given by $m_{j h}$ for self-insured consumers and $\chi_{P} m_{j h}$ for consumers who purchased private health insurance in the preceding period. 
Consumers that choose to go on Emergency Relief have to forfeit all assets and work zero hours. In return, the government covers all out-of-pocket health care expenses and provides the consumer with a minimum consumption level, ‥ Recall that consumers who choose to go on Emergency Relief suffer the same utility cost as those that enroll in Medicaid. The value of going on Emergency Relief is then given by

$$
\begin{array}{ll}
V^{F}(s)= & U(\underline{\mathrm{c}}, 0, e, 1)-\kappa+\beta \psi_{j e h} \mathbb{E}_{\eta^{\prime} \mid \eta} \mathbb{E}_{h^{\prime} \mid j e h} V\left(s^{\prime}\right) \\
\text { s.t. } \quad & a^{\prime}=0 \\
& i^{\prime}=i_{S} .
\end{array}
$$

\subsubsection{Young consumers with employer-provided health insurance}

Let $V^{E}(s)$ denote the value of being on employer-provided health insurance. Young consumers with employer insurance solve the same problem as young consumers without employer insurance, with the exception that the former group is not allowed to purchase private health insurance. Young consumers with employer insurance solve the following problem:

$$
V(s)=\max \left\{V^{E}(s), V^{F}(s)\right\},
$$


where for simplicity we have used the same notation as in Equation (10), even though the two $V(s)$ are not the same. The value of being on employer-provided health insurance, $V^{E}(s)$, is given by

$$
\begin{aligned}
& V^{E}(s)=\max _{c, a^{\prime}, \ell, i_{C A I D}} U\left(c, \ell, e, i_{C A I D}\right)+\beta \psi_{j e h} \mathbb{E}_{\eta^{\prime} \mid \eta} \mathbb{E}_{h^{\prime} \mid j e h} V\left(s^{\prime}\right) \\
& \text { s.t. } \quad\left(1+\tau_{c}\right) c+\left(1+g_{z}\right) a^{\prime}+m_{o p}+\mathbf{1}_{\ell>0} \pi_{E}=w\left(1-\tau_{\ell}\right) \eta \xi_{h} \epsilon_{j e} \ell+\left(1+r\left(1-\tau_{k}\right)\right)\left(a+B_{j}\right) \\
& m_{o p}= \begin{cases}\chi_{E} m_{j h} & \text { if } \mathbf{1}_{C A I D}(s, \ell)=0 \\
\chi_{E} \chi_{C A I D} m_{j h} & \text { if } \mathbf{1}_{C A I D}(s, \ell)=1\end{cases} \\
& \ell \in \begin{cases}0, \ell_{p}, \ldots, \ell_{e} & \text { if sick } \\
\ell_{p}, \ldots, \ell_{e} & \text { if healthy }\end{cases} \\
& c, a^{\prime} \geq 0 \\
& i^{\prime}=i_{E} \\
& i_{C A I D} \in\{0,1\} \text {. }
\end{aligned}
$$

Out-of-pocket health care expenses are given by $\chi_{E} m_{j h}$ for consumers on employer insurance. All consumers on employer insurance who work must pay a premium $\pi_{E}$. We assume that healthy consumers on employer insurance have to supply a minimum of $\ell_{p}>0$ hours. Sick consumers, on the other hand, are free to choose zero hours. In the model, consumers are considered sick if they have a catastrophic health state (see Subsection 3.1.8 for details). Finally, the value of going on Emergency Relief is the same as above, with the exception that consumers continue to be eligible for employer-provided insurance in the following period, $i^{\prime}=i_{E}$

\subsubsection{Old consumers}

Let $V^{R}(s)$ denote the value of an old consumer of type $s$. Old consumers solve the same problem as young consumers without employer-provided health insurance:

$$
V(s)=\max \left\{V^{R}(s), V^{F}(s)\right\}
$$


where $V^{R}(s)$ is given by

$$
\begin{aligned}
V^{R}(s)= & \max _{c, a^{\prime}, \ell, i^{\prime}, i_{C A I D}} U\left(c, \ell, e, i_{C A I D}\right)+\beta \psi_{j e h} \mathbb{E}_{\eta^{\prime}|\eta|} \mathbb{E}_{h^{\prime} \mid j e h} V\left(s^{\prime}\right) \\
\text { s.t. } & \left(1+\tau_{c}\right) c+\left(1+g_{z}\right) a^{\prime}+m_{o p}+\mathbf{1}_{i^{\prime}=i_{P}} \pi_{j e h}=\widehat{S S}_{e j}+w\left(1-\tau_{\ell}\right) \eta \xi_{h} \epsilon_{j e} \ell+\left(1+r\left(1-\tau_{k}\right)\right) a
\end{aligned}
$$

Note that old consumers are allowed to work in the model. This is motivated by the observation that nearly 20 percent of individuals aged 65 and older still participate in the workforce. Old consumers receive transfers from the government in the form of Social Security, $\widehat{S S}_{e j}$. To account for the fact that up to 50 percent of Social Security benefits are taxable if the individual's income exceeds $\$ 25,000$ and up to 85 percent of benefits are taxable if the individual's income exceeds $\$ 34,000$ (see Social Security Administration, 2019), we use the following formula for Social Security benefits, $\widehat{S S}_{e j}$. We let $\widehat{S S}_{e j}$ be equal to $S S_{e j}$ if total income, $0.5 S S_{e j}+w \eta \xi_{h} \epsilon_{j e} \ell+r a$, is less than a threshold $y_{1} ; \widehat{S S}_{e j}=S S_{e j}\left(1-0.5 \tau_{\ell}\right)$ if total income lies between $y_{1}$ and $y_{2}$; and $\widehat{S S}_{e j}=S S_{e j}\left(1-0.85 \tau_{\ell}\right)$ if total income exceeds $y_{2}$, where $y_{1}$ and $y_{2}$ correspond to $\$ 25,000$ and $\$ 34,000$. Finally, old consumers are covered by Medicare. Accordingly, their out-of-pocket health care expenses are given by $\chi_{C A R E} m_{j h}$ for self-insured consumers and $\chi_{C A R E} \chi_{P} m_{j h}$ for consumers that purchased private health insurance in the preceding period. In addition, if the consumer is eligible for Medicaid and chooses to enroll, a share $1-\chi_{C A I D}$ of her out-of-pocket health care expenses will be covered by Medicaid. 


\subsection{Definition of equilibrium}

Given a consumption tax rate, $\tau_{c}$; capital income tax rate, $\tau_{k}$; government consumption, $G_{c}$; government

debt, $D$; coinsurance rates $\chi_{P}, \chi_{E}, \chi_{C A R E}$, and $\chi_{C A I D}$; and initial conditions for capital $K_{1}$ and the measure of types $\Phi_{1}$; an equilibrium in our model is a sequence of model variables such that:

1. Given prices, insurance premia, government policies, and accidental bequests, consumers maximize utility subject to their constraints.

2. Factor prices satisfy marginal product pricing conditions:

$$
\begin{aligned}
& r=\theta^{1-\alpha} \alpha\left(\frac{N}{K}\right)^{1-\alpha}-\delta \\
& w=\theta^{1-\alpha}(1-\alpha)\left(\frac{K}{N}\right)^{\alpha} .
\end{aligned}
$$

3. Goods, capital, and labor market clearing conditions are met:

$$
\begin{gathered}
C+G_{c}+M+\left(1+g_{z}\right)\left(1+g_{n}\right) K^{\prime}=K^{\alpha}(\theta N)^{1-\alpha}+(1-\delta) K \\
K^{\prime}+D^{\prime}=\frac{\int a^{\prime}(s) \Phi(d s)}{\left(1+g_{n}\right)}+\frac{\int \mathbb{I}_{i^{\prime}(s)=i_{P}} \pi_{j e h} \Phi(d s)}{\left(1+g_{z}\right)\left(1+g_{n}\right)} \\
N=\int \eta \epsilon_{j e} \xi_{h} \ell(s) \Phi(d s) .
\end{gathered}
$$

4. Accidental bequests are given by

$$
B_{j}^{\prime}=\frac{\int\left(1-\psi_{j e h}\right) a^{\prime}(s) \Phi(d s)}{\left(1+g_{n}\right) \int \Phi\left(d s \mid j \in\left\{j_{1}, \ldots, j_{2}\right\}\right)}
$$

where $j_{1}$ and $j_{2}$ refer to 50 - and 60 -year-old consumers.

5. Insurance market clearing conditions are met.

6. Government policies satisfy the government budget constraint.

7. The aggregate law of motion for $\Phi$ is induced by the policy functions and the exogenous stochastic processes for idiosyncratic risk. 


\section{Calibration}

We calibrate the model in two steps. In the first step, we calibrate a set of parameters outside the model equilibrium. In the second step, we assume that the initial balanced growth economy is 2005 and jointly calibrate the remaining parameters to match moments in the U.S. economy in that year.

\subsection{Parameters determined outside the model equilibrium}

The following subsections discuss the parameters that are determined outside the model equilibrium. These parameters are presented in Table 1.

\subsubsection{Life cycle}

A period in the model is 1 year. In our model, consumers enter the economy at age 20 . We set the retirement age, $j_{r}$, to 46, implying that consumers start receiving Medicare and Social Security benefits at age 65 . The maximum life span, $J$, is set to 81 , such that consumers live at most 100 years.

\subsubsection{Risk aversion and indivisible labor}

We set the risk aversion parameter, $\sigma$, to 3.964, which, together with the calibrated value for $\gamma$ (see Subsection

3.2 below), implies an intertemporal elasticity of substitution, $\frac{-u_{c}}{u_{c c} c}=\frac{-1}{\gamma(1-\sigma)-1}$, of 0.5 . The discrete grid for labor supply is $\ell \in\left\{0, \ell_{p}, \ldots, \ell_{f}, \ldots, \ell_{e}\right\}$, where $\ell_{p}, \ell_{f}$, and $\ell_{e}$ refer to part-time, full-time, and extra time, respectively. We set $\ell_{f}$ to 0.333 (that is, 37.3 hours per week given a time endowment of 112 hours per week), $\ell_{p}$ to 50 percent of full-time, and $\ell_{e}$ to 150 percent of full-time. We use 5 equally spaced grid points between $\ell_{p}$ and $\ell_{e}$.

\subsubsection{Cost of going to college}

We capture some of the costs of going to college by means of a time cost, $f_{e}$. Given that we define collegeeducated individuals in the data as individuals with at least a bachelor's degree or a minimum of 4 years of college, we assume that college-educated consumers in the model spend 4 years in college. In particular, we assume that 20- to 23-year-olds with a college degree spend 50 percent of their time endowment each year in college, which corresponds to a time cost of 0.500 in each of the first 4 years given our assumption of a unit time endowment. 


\subsubsection{Technology}

We set the growth rate of labor-augmenting technological progress, $g_{z}$, to 0.020 to match average technology growth over the post-war period. The capital share, $\alpha$, is set to 0.360 . Lastly, we set the depreciation rate, $\delta$, to 0.059 , as in Castañeda et al (2003).

\subsubsection{Idiosyncratic labor productivity}

The idiosyncratic labor productivity in the model comprises the stochastic component, $\eta$, the health-specific stochastic component, $\xi_{h}$, and the age- and education-specific deterministic component, $\epsilon_{j e}$. The parameters of the idiosyncratic stochastic process are calibrated jointly in equilibrium, as will be discussed in Subsection 3.2. For the health-specific stochastic component, we set $\xi_{h}$ to 1 for consumers with low and high health care expenses and to 0 for consumers with catastrophic expenses (see Subsection 3.1.8 for details about the health care expenditure states). For the age- and education-specific deterministic component, we use the estimates in Conesa et al (2018) (see the supplementary appendix for details).

\subsubsection{Taxes}

We compute effective tax rates for consumption and capital income using OECD data on national accounts and tax revenues, following the methodology pioneered by Mendoza et al (1994). We use the average value between 2005 and 2009, which results in a consumption tax rate, $\tau_{c}$, of 4.7 percent and a capital income tax rate, $\tau_{k}$, of 32.1 percent. As noted in Section 2.4, the labor tax rate, $\tau_{\ell}$, is set to balance the government budget every period and hence is determined endogenously in equilibrium.

\subsubsection{Health insurance}

We use the following approach to compute the coinsurance rates for private insurance, employer-provided insurance, and Medicaid. Using data from the Medical Expenditure Panel Survey (MEPS), we first derive each individual's primary insurance provider, defined as the insurer that pays for the largest share of the individual's health care expenses. To illustrate, if Medicaid and private health insurance both cover a share of the individual's health care expenses, but Medicaid covers the largest share, then we let Medicaid be defined as this individual's primary insurance provider. Next, we pool all the individuals in the MEPS with the same primary insurance provider and compute the average share of expenses paid by this insurance provider. Let these values be denoted by $\tilde{\chi}_{P}, \tilde{\chi}_{E}$, and $\tilde{\chi}_{C A I D}$ for individuals with private health insurance, employer-provided health insurance, and Medicaid as their primary insurance provider, respectively. We then let the coinsurance rate for private insurance, employer-provided insurance, and Medicaid be given by 
$\chi_{P}=1-\tilde{\chi}_{P}, \chi_{E}=1-\tilde{\chi}_{E}$, and $\chi_{C A I D}=1-\tilde{\chi}_{C A I D}$. Finally, we set the coinsurance rate on Medicare, $\chi_{C A R E}$, to match the observation that about 50 percent of the elderly's total health care expenses are covered by Medicare in the United States.

We use the following approach to compute the Medicaid eligibility criteria. We first get data on statespecific Medicaid eligibility criteria from the Kaiser Family Foundation. This data is reported in the Online Appendix. We then set the categorical income limit, $y^{C A T}$, the medically needy income limit, $y^{M N}$, and the medically needy asset limit, $a^{M N}$, to match the corresponding weighted average limits in the data, with weights given by each state's share of total health care expenses. To ensure a balanced growth path, we assume that the Medicaid income and asset thresholds grow at the rate of technological progress, $g_{z}$.

\subsubsection{Health care expenses and transition probabilities}

We split health care expenses into three categories: low, high, and catastrophic. To identify these expenses in the MEPS, we first pool all health care expenses for each age and educational group (college and noncollege) and compute the 60th and 99.9th percentile. We then identify age- and education-specific low, high, and catastrophic health care expenses as the average value between the 0 and 60 th percentile, the 60 th and 99.9th percentile, and the 99.9th and 100th percentile, respectively. Since the MEPS top-codes age at age 85, we extrapolate health care expenses for consumers aged 85 to 100 using a log-linear trend. Finally, for each age group, we use the average value of health care expenses between college and non-college-educated individuals.

The health transition matrix must guarantee that, for each age and educational group, 60.0, 39.9, and 0.1 percent of consumers have low, high, and catastrophic health care expenses, respectively. The following discussion explains how we adjust the health transition probabilities. Using our MEPS sample, we first estimate age-, health-, and education-specific health transition probabilities by running an ordered probit regression of the next period's health on current age, age-squared, education, health, and interaction terms. Next, we iterate on the transition matrix until the probabilities guarantee that, for each age and educational group, the correct percentage of consumers transition to each health state. That is, we iterate on the tran-

sition matrix, $Q_{j, e}(h, H)$, until $x^{T} Q_{j, e}(h, H)=x^{T}$, where $x^{T}=[0.600,0.399,0.001]$ denotes the probability distribution of consumers across health states. Note that this is an augmented version of the RAS method, which is a method used to generate matrices that satisfy pre-specified row and column sum constraints.

\subsubsection{Survival probabilities}

In the model, survival probabilities vary with age, education, and health, $\psi_{j e h}$. These probabilities cannot be derived directly from the MEPS, because the MEPS does not sample institutionalized individuals. Survival 
probabilities estimated from the MEPS will therefore be upwardly biased. Moreover, the estimates are not guaranteed to match the education survival premium, defined as the difference in age-specific survival probabilities between college and non-college-educated individuals. Building on Attanasio et al. (2010), we therefore adjust the estimated survival probabilities to match both the age-specific survival probabilities in the data and the education survival premium. Details about how we adjust the survival probabilities are given in the Online Appendix.

\subsubsection{College attainment and growth rate of 20-year-old population}

For college attainment, we use data from the U.S. Census Bureau. For the initial balanced growth economy, we use the average value of the percentage of college graduates in the population aged 25 and older from 2005-2009. To compute the growth rate of the population of 20-year-olds, we use population estimates from the United Nations' World Population Prospects: The 2012 Revision. This data set provides population estimates for 5-year age groups $\left(20-24,25-29\right.$, etc.). We compute $g_{n, t}$ as the number of individuals aged 20-24 in period $t$ divided by the number of individuals aged 20-24 in period $t-1$ and convert the 5-year estimates to annual estimates. For the initial balanced growth economy, we use the average $g_{n, t}$ from 1980 to 2005 .

\subsection{Parameters determined jointly in equilibrium}

Table 2 reports the parameters that are determined jointly in equilibrium. The parameters are calibrated jointly to match key moments of the U.S. economy during the period 2005-2009 (for simplicity, we refer to the period 2005-2009 as 2005 below).

We normalize $\theta$ such that GDP per capita is equal to 1 in 2005. The discount factor is calibrated to match a capital-to-output ratio of 3 , which is a common value used in the literature. We calibrate the consumption share in the utility function, $\gamma$, such that average hours worked per employee are equal to full-time, 0.333. We calibrate the Social Security replacement rates, $b_{e}$, to match average Social Security benefits across individuals with and without a college degree. We calibrate the percentage of 20-year-olds that qualify for employer-provided insurance to match the percentage of the working-age population with employerprovided insurance in the data. We calibrate government consumption, $G_{c}$, and government debt, $D$, to match government consumption-to-output and government debt-to-output, respectively. We scale health care expenditures to match a health care expenditure-to-GDP ratio of 15.2 percent. The consumption floor,

$\underline{c}$, is calibrated to match the average annual Supplemental Nutrition Assistance Program benefits reported by the United States Department of Agriculture. The utility cost of going on Medicaid and Emergency Relief, 
$\kappa$, is calibrated such that the model matches the percentage of health care expenses covered by Medicaid. To ensure a balanced growth path, we assume that the minimum consumption level and the utility cost of going on Medicaid and Emergency Relief grow at the rate of technological progress.

Finally, we follow Castañeda et al. (2003) and calibrate the parameters of the stochastic labor productivity process to match the empirical earnings distribution in the United States. We choose a right-skewed productivity shock process to match the top decile of the earnings distribution and calibrate the variance of the process to match the dispersion observed in the data.

\subsection{Comparing the Frisch elasticity in the model and the data}

The extent to which the government has to increase the labor tax rate to finance the costs of an aging population depends critically on the Frisch elasticity of labor supply. This follows because a higher labor tax rate reduces incentives to work. The Frisch elasticity determines the responsiveness of hours worked to changes in the post-tax wage rate - holding constant the marginal utility of wealth - and hence determines how much consumers will reduce their labor supply in the event of a tax increase. We end this section by comparing the Frisch elasticity of labor supply in the model with estimates from the literature.

We estimate the micro Frisch elasticity of labor supply for each consumer in the initial balanced growth economy by computing the responsiveness of hours worked to a 5-percent transitory increase and to a 5percent transitory decrease in hourly earnings. We focus on responses to transitory shocks to minimize the wealth effects of the shocks. Moreover, we focus solely on changes along the intensive margin by excluding consumers who do not work with or without the transitory shocks. The average Frisch elasticity for 20- to 64-year-old consumers in the model is 0.725 for the positive shock and 1.157 for the negative shock, both of which are somewhat higher than the value of 0.5 commonly used in the literature (see, for example, Blundell and MaCurdy 1999, Chetty et al. 2011, and Keane 2011 for reviews of this literature).

Figure 1 plots the estimated micro Frisch elasticities across all 20- to 64-year-old consumers in the model. The solid black line plots the elasticities for the positive earnings shock, and the dotted red line plots the elasticities for the negative shock. As illustrated in the graph, 85.4 percent of the consumers do not adjust their hours worked in response to a 5-percent transitory increase in hourly earnings, because labor supply is indivisible in the model. For 8.2 percent of the consumers, the elasticity is greater than 0 but no greater than 4. This is due to the substitution effect given our assumption about preferences (see Equation 5) combined with the indivisibility of labor supply. Note that 0.8 percent of consumers respond to the positive earnings shock by reducing hours worked, thereby leading to negative Frisch elasticities for these consumers. This follows because some consumers reduce their hours worked in response to the positive earnings shock 
to maintain eligibility for Medicaid. The positive earnings shock can also make consumers ineligible for Medicaid even if they choose to work the minimum number of hours (part-time). These consumers may respond to the positive earnings shock by significantly increasing their hours worked, thereby leading to high positive Frisch elasticities. Accordingly, for 5.8 percent of the consumers, the elasticity is greater than 4 .

\section{Comparative statics: College attainment, fertility, and longevity}

In this section, we perform comparative statics exercises with balanced growth paths for three channels that contribute to an increase in the old age dependency ratio: increasing college attainment, decreasing fertility, and increasing longevity. We assume that the initial balanced growth economy is 2005. For the comparative statics, we use projections for the year 2100, discussed in the next subsection.

\subsection{Projections of college attainment, fertility, and longevity for 2100}

College attainment, as measured by the percentage of people 25 years and older with a college degree, has increased continuously in the United States since 1960. This can be seen from the left panel of Figure 2, which shows that the share of the population 25 years and older with a college degree increased from 9 to 31 percent between 1960 and 2010. Given this observation, we project college attainment for 2100 by first estimating a linear trend for the percentage of the population aged 25 and older with a college degree from 1960 to 2010. We then extrapolate this trend to 2100 and assume that it stays fixed in the balanced growth path after that. The comparison between the data and the regression line between 1960 and 2010 and the extrapolated trend until 2100 is illustrated in the left panel of Figure 2. As illustrated in the graph, if the trend in college attainment continues, then the percentage of the population with a college degree will increase from 29 percent in 2005 to 70 percent in 2100 . We view the 2100 projection for college attainment as an upper bound and perform comparative statics for different levels of college attainment. Although our projections are likely to provide an upper bound, they are consistent with recent trends in college enrollment rates, especially among women. In particular, our projected trend for college attainment implies that 41 percent of 20-year-old consumers in the model will be enrolled in college in 2015. This is consistent with recent data from the National Center for Education Statistics, which show that more than 40 percent of 18to 24-year-olds, and approximately 45 percent of 18- to 24-year-old women, are currently enrolled in college. Our projection that college attainment will continue to increase in the United States is also consistent with Eckstein et al (2019). They develop a life cycle model to decompose how much of the increase in female college attainment - from less than 10 percent in 1960 to almost 40 percent in 2010, see the right panel of Figure 2 - can be explained by changing labor and marriage market conditions versus changing preferences. 
They find that a large share of the increase in female college attainment is generated by women whose mothers went to college, which gives them an enhanced taste for college. Accordingly, they argue that it is likely that future cohorts of women will continue to have higher college attendance rates simply because their mothers were more educated.

In our model, changes in fertility rates are captured through changes in the population growth rate of 20 -year-olds. To obtain estimates for the population growth rate of 20 -year-olds in 2100 , we use population forecasts for the years 2095 and 2100 from the United Nations' World Population Prospects: The 2012 Revision, the same data set used for the 2005 estimate. The U.N. forecasts are given for alternative simulations based on different assumptions about fertility, mortality, and migration. We use the median forecasts for fertility and mortality. Furthermore, because our model does not feature migration, we use the forecasts that are based on the assumption of zero migration. Table 3, which reports the value for college attainment and fertility in the initial balanced growth path and the corresponding projected values for 2100, shows that the population growth rate of 20-year-olds is projected to decrease from 0.30 percent to -0.05 percent by 2100 .

In our model, increased longevity is captured through increasing age-specific survival probabilities. For 2005, we use the age-, education-, and health-specific survival probabilities discussed in Subsection 3.1.9. For the 2100 projection, we first compute age-specific survival probabilities for the years 2005 and 2100 using the U.N. data. We then calculate the factor by which we need to increase the age-specific survival probabilities in 2005 to match the corresponding estimates in 2100. Finally, we scale the age-, education-, and health-specific 2005 survival probabilities by our scaling factor. Note that our approach relies on the assumption that, for each age, the health and education survival premia discussed in Subsection 3.1.9 are the same in 2100 as in 2005. The derived survival probabilities are depicted in Figure 3. The left panel of Figure 3 plots the age- and health-specific survival probabilities in 2005 (solid lines) and 2100 (dashed lines) for non-college-educated consumers, and the right panel of Figure 3 plots the corresponding probabilities for college-educated consumers. Here, low, high, and catastrophic refer to consumers with low, high, and catastrophic health care expenses, as discussed in Subsection 3.1.8.

\subsection{Individual implications of college attainment, fertility, and longevity}

We perform comparative statics exercises for different levels of the 2100 projections for college attainment, fertility, and longevity. To illustrate, a value of 0 for fertility refers to the case of $g_{n}=g_{n, 2005}$, a value of 0.5 refers to the case of $g_{n}=0.5 g_{n, 2005}+0.5 g_{n, 2100}$, and a value of 1 refers to the case of $g_{n}=g_{n, 2100}$. In the tables, the three cases are referred to as increased college attainment, decreased fertility, and increased longevity. 
We start by studying the implications for the old age dependency ratio. Table 4 shows that all three channels lead to a higher old age dependency ratio. Increasing college attainment increases the old age dependency ratio by 3.5 percentage points because college graduates have higher life expectancy than noncollege graduates. Decreasing fertility increases the old age dependency ratio by 4.6 percentage points because it leads to relatively fewer young consumers. Lastly, increasing longevity increases the old age dependency ratio by 16.2 percentage points because it leads to relatively more older consumers.

Although all three channels contribute to a higher old age dependency ratio, they have different fiscal implications. In particular, as shown in Table 4, we find that increasing college attainment allows the government to reduce the labor tax rate by 7.1 percentage points, whereas decreasing fertility and increasing longevity require the government to increase the labor tax rate by 3.6 and 6.1 percentage points, respectively. Increasing college attainment allows the government to reduce the labor tax rate for several reasons. First, and most importantly, since college-educated consumers have higher labor productivity than non-collegeeducated consumers, an increase in college attainment leads to an economy with more productive workers. Second, hours worked per capita and labor force participation rates among both workers between the ages of 20 and 64 and those aged 65 and older are higher in the economy with higher college attainment. As reported in Table 4, these effects contribute to an increase in effective labor per capita. Higher effective labor per capita, in turn, leads to higher government revenues from labor taxation, thereby allowing the government to reduce the labor tax rate.

Third, college graduates are less likely to enroll in Medicaid and Emergency Relief. Increasing college attainment thus lowers government spending on these programs, thereby contributing to a lower labor tax rate. This can be seen from Table 5 , which shows how the health care expenditure distribution by insurance provider changes as we increase college attainment, decrease fertility, and increase longevity. In particular, the table shows that increasing college attainment lowers the share of health care expenses covered by Medicaid from 15.4 to 11.2 percent and lowers the share of health care expenses covered by Emergency Relief from 1.9 to 1.6 percent. This is because college graduates, on average, have both higher earnings and wealth. Hence, in the model, enrolling in Medicaid and Emergency Relief is more costly for them. Table 6 shows that the reduction in government spending on Medicaid and Emergency Relief following the increase in college attainment contributes to lower public health care spending per capita. In contrast, decreasing fertility and increasing longevity lead to higher spending on Medicaid and Emergency Relief, thereby increasing public health care spending per capita.

A fourth reason why higher college attainment allows the government to reduce the labor tax rate is that higher college attainment leads to higher wages, thereby further increasing government revenues from labor taxation. This is reported in Table 6 . The wage rate goes up because the increase in college attainment 
leads to more capital per capita relative to effective labor per capita. This outcome is driven by the fact that college-educated consumers save more than non-college-educated consumers. College graduates save more because they have higher labor earnings, higher life expectancy, and a stronger precautionary savings motive, because enrolling in Medicaid and Emergency Relief is more costly for them.

Fifth, the increase in capital accumulation due to higher college attainment leads to a 1.3 percentage point reduction in the interest rate. Lower interest rates reduce interest payments on government debt, which accounts for 6.8 percent of total government spending in the initial balanced growth economy. As shown in Table 6, we find that higher college attainment reduces interest payments on government debt per capita by 36.9 percent.

Finally, as shown in Table 6, higher college attainment leads to both higher consumption tax revenues per capita and higher capital income tax revenues per capita. This follows because college graduates both consume and save more than non-college graduates. In contrast, decreasing fertility and increasing longevity lead to lower government revenues from consumption and capital income taxation.

The forces that we have mentioned so far contribute to lower labor taxes, but there are forces that move in the opposite direction. In particular, increasing college attainment leads to higher spending on Medicare. This follows because higher college attainment increases average life expectancy in the population. As reported in Table 5, we find that higher college attainment increases the share of total health care expenses covered by Medicare from 25.0 to 26.4 percent. By comparison, we find that the projected increase in longevity increases the share of total health care expenses covered by Medicare from 25.0 to 30.7 percent. Moreover, as reported in Table 6, we find that higher college attainment increases Social Security spending per capita by 23.5 percent. This follows because college-educated consumers have higher life expectancy than non-college-educated consumers and because college graduates claim higher Social Security benefits due to higher lifetime labor earnings. Consequently, higher spending on Medicare and Social Security partially offset the reduction in the labor tax rate brought about by higher college attainment.

The Online Appendix reports the results from an alternative exercise where we change the projection for fertility to match the projected increase in the old age dependency ratio due to increasing college attainment (from 35.3 to 38.8 percent). Similarly, we change the projection for longevity to match the projected increase in the old age dependency ratio due to increasing college attainment. This exercise allows us to compare the implications of the three channels of aging when all channels lead to the same increase in the old age dependency ratio. In this case, we find that decreasing fertility and increasing longevity require the government to increase the labor tax rate by 2.7 and 1.2 percentage points, respectively. Further details are given in the Online Appendix. 


\subsection{Joint implications of college attainment, fertility, and longevity}

We now study the joint implications of increasing college attainment, decreasing fertility, and increasing longevity. In particular, we use the 2100 projections for fertility and longevity but vary the increase in college attainment from 0 to 100 percent of its projected increase. The results are reported in Table 7 . The first column reports the results when we only decrease fertility and increase longevity (that is, we set college attainment equal to its value in 2005). The last two columns report the results when we increase college attainment to 50 percent and 100 percent of its projected increase, respectively. To illustrate, Table 7 shows that the combination of decreasing fertility and increasing longevity leads to an increase in the old age dependency ratio from 35.3 to 58.7 percent. The final column of Table 7 shows that all three channels of aging lead to an increase in the old age dependency ratio from 35.3 to 64.0 percent if college attainment increases to its projected value in 2100 (that is, if the percentage of the population aged 25 and older with a college degree increases to 70 percent).

The first part of Table 7, which reports the old age dependency ratio, shows that the joint effect of college attainment, fertility, and longevity is greater than the sum of the individual effects $(64.0-35.3=$ $28.7>24.3=3.5+4.6+16.2$ ) . Hence, higher college attainment not only increases the old age dependency ratio but also amplifies the increase in the old age dependency ratio brought about by decreasing fertility and increasing longevity. To understand this amplification effect, consider the following example. Let $\psi_{c}$ and $\psi_{n c}$ denote the survival probability of college-educated and non-college-educated consumers, and let $\omega_{c}$ denote the mass of college-educated consumers. The average survival probability is then given by $\omega_{c} \psi_{c}+\left(1-\omega_{c}\right) \psi_{n c}$. Next, let $\Lambda_{\psi}$ denote the factor by which we increase survival probabilities to account for increased longevity, and let $\Lambda_{c o l}$ denote the corresponding factor by which we increase the share of college-educated consumers to account for increased college attainment. The average survival probability in the economy after we account for increased longevity and increased college attainment is then given by $\Lambda_{\psi}\left(\Lambda_{c o l} \omega_{c} \psi_{c}+\left(1-\Lambda_{c o l} \omega_{c}\right) \psi_{n c}\right)$. Here, $\Lambda_{\psi}>1$ leads mechanically to a higher old age dependency ratio because it increases life expectancy, thereby leading to relatively more old consumers. Similarly, $\Lambda_{c o l}>1$ leads mechanically to a higher old age dependency ratio because college-educated consumers have higher life expectancy than non-college educated consumers, $\psi_{c}>\psi_{n c}$. Moreover, the interaction between increased college attainment and increased longevity further increases the old age dependency ratio. This follows from the interaction between $\Lambda_{\psi}$ and $\Lambda_{c o l}$ in the expression for the average survival probability, which implies that the increase in the average survival probability - and therefore the increase in the old age dependency ratio-due to increased longevity, $\Lambda_{\psi}$, will be higher the higher the increase in college attainment, $\Lambda_{c o l}$.

We then study the implications for prices. We find that higher college attainment not only reduces the 
interest rate but also amplifies the reduction in the interest rate due to decreasing fertility and increasing longevity. Analogously, higher college attainment amplifies the increase in the wage rate brought about by the other channels. These interaction effects have implications for government spending. Recall from Table 6 that the three channels lead to a combined increase in Social Security spending per capita of 59.7 percent. Table 7 shows that the interaction effects between the three channels of aging lead to an additional 9.5 percentage point increase in Social Security spending per capita. This is partially due to the amplified increase in the wage rate. Table 7 also shows that the reduction in the interest rate due to higher college attainment and increased longevity leads to a 62.8 percent reduction in interest payments on government debt per capita.

Next, we study the implications for consumption tax revenues per capita and capital income tax revenues per capita. Table 7 shows that consumption tax revenues per capita are higher in the model with all three channels of aging when college attainment is equal to its 2100 projected value. This shows that the increase in consumption tax revenues due to higher college attainment more than offsets the reduction in consumption tax revenues caused by decreasing fertility and increasing longevity. Recall from Table 6 that higher college attainment increases capital income tax revenues per capita, whereas decreasing fertility and increasing longevity reduce capital income tax revenues per capita. Our results show that adding higher college attainment to the model with decreasing fertility and increasing longevity leads to a further reduction in capital income tax revenues per capita. This follows because higher college attainment amplifies the reduction in the interest rate caused by decreasing fertility and increasing longevity, which in turn lowers government revenues from capital income taxation.

We find that decreasing fertility and increasing longevity require the government to increase the average labor tax rate from 33.5 to 47.1 percent. As shown in Table 7, adding increasing college attainment to this model lowers the required increase in the labor tax rate by 12.0 percentage points. Consequently, we find that all three channels of aging require the government to increase the average labor tax rate from 33.5 to 35.1 percent if college attainment increases to its projected value in 2100.

\subsection{General equilibrium effects of college attainment, fertility, and longevity}

Next, we compare the results from the benchmark closed economy with the corresponding results from a small open economy with a constant and exogenous interest rate. By construction, the detrended wage rate is also constant in the small open economy. All other variables, such as the labor tax rate and the employerprovided insurance premium, are determined endogenously in equilibrium. We do this not because we think the United States is well modeled as a small open economy, but because it enables us to quantify the general 
equilibrium effects of higher wages and lower interest rates brought about by higher capital accumulation.

We study the tax implications of introducing higher college attainment into two different versions of the model with decreasing fertility and increasing longevity: one, our benchmark general equilibrium model; and the other, the small open economy model with constant wages and interest rate. We continue to use the 2100 projections for fertility and longevity but vary the increase in college attainment from 0 to 100 percent of its projected increase. We compare the change in tax revenues and the resulting change in the labor tax rate required to balance the government budget. These results are reported in Table 8 .

We find that the capital stock increases in both the general equilibrium model and the small open economy model. In the general equilibrium model, however, the increase in the capital stock also leads to higher wages and lower interest rates. Higher wages lead to higher earnings, not only because of the direct effect of higher wages but also because higher wages induce consumers to work more. Consequently, we find that effective labor per capita increases by 8.0 percent when we introduce all three channels of aging in the general equilibrium model but increases by 4.7 percent in the small open economy model. Higher wages and higher effective labor per capita contribute to higher labor income tax revenues.

Higher wages, however, also lead to higher Social Security benefits and therefore higher government expenditures. More importantly, the reduction in the interest rate in the general equilibrium model lowers government revenues from capital income taxation. Accordingly, we find that the three channels of aging reduce capital income tax revenues per capita by 13.1 percent in the general equilibrium model but increase capital income tax revenues per capita by 89.4 percent in the small open economy model. As a result, we find that the labor tax rate required to balance the government budget is higher under general equilibrium. In particular, we find that the three channels of aging require the government to increase the average labor tax rate by 1.6 percentage points in the general equilibrium model if college attainment increases to its projected value in 2100 . In contrast, we find that the three channels of aging allow the government to reduce the average labor tax rate by 6.0 percentage points in the small open economy model. Note that the reduction in the labor tax rate in the small open economy model is partially due to higher consumption tax revenues per capita in the small open economy model than in the general equilibrium model. This follows because lower labor tax rates in the small open economy model facilitate higher consumption, thereby leading to higher consumption tax revenues per capita.

\subsection{Implications for welfare}

Lastly, we study the welfare implications of increasing college attainment. To do this, we first solve for two demographic transitions: one transition where we decrease fertility and increase longevity, and another 
transition where we introduce all three channels of aging. We then quantify how much better off consumers are in the demographic transition with increasing college attainment by comparing the welfare implications of these two transitions. We use the 2100 projections for college attainment, fertility, and longevity that were discussed in Subsection 4.1 and interpolate to obtain values between 2005 and 2100. Although we assume that college attainment, fertility, and longevity do not change after 2100 , the economy will not be on a balanced growth path in 2100. We therefore solve for a transition that lasts until 2210 .

Let $V_{t}^{f+l}(s)$ denote the value of a consumer of type $s$ that enters the transition with decreasing fertility and increasing longevity in period $t$ of the transition. Similarly, let $V_{t}^{\text {all }}(s)$ denote the value of a consumer of type $s$ that enters the transition with all three channels of aging in period $t$ of the transition. Following Conesa et al. (2018), we quantify the welfare implications of increasing college attainment by means of wealth equivalent variation (WEV). To do this, we first compute the dollar value of how much wealth must change in the transition with decreasing fertility and increasing longevity to make the consumer weakly better off in this transition than in the transition with all three channels of aging. Given that consumers are not allowed to borrow, there exists a lower bound for this change in wealth. For each type $s$, we therefore compute the minimum change in wealth, $W E V(s)$, that satisfies the following constraints:

$$
\begin{array}{ll}
\min & W E V(s) \\
\text { s.t. } & V_{t}^{f+l}(j, e, h, \eta, a+W E V(s), i) \geq V_{t}^{\text {all }}(j, e, h, \eta, a, i) \\
& a+W E V(s) \geq 0
\end{array}
$$

We then compute the average welfare effect of increasing college attainment by integrating across consumers:

$$
W E V=\int W E V(s) \Phi(d s)
$$

A key advantage of WEV compared with the more commonly used consumption equivalent variation (CEV) is that the former allows for aggregation across consumers, which in turn enables us to compute the average welfare implications of increasing college attainment. Moreover, unlike CEV, WEV takes into account that consumers re-optimize their decisions following the wealth transfer.

We start by studying the welfare implications for 20-year-old consumers under the veil of ignorance who enter the economy in period $t$ of the transition. By "veil of ignorance", we mean that we focus on consumers who have zero assets and for whom the education type (college or non-college), but not the stochastic components of productivity and health, have been revealed. For simplicity, we refer to the welfare implications for 20-year-old consumers under the veil of ignorance as the ex-ante welfare implications. We report the welfare results from the productivity-detrended models. Figure 4 plots the one-time transfer 
required to make the consumer who enters the transition with decreasing fertility and increasing longevity in year $t$ indifferent between entering that transition and entering the transition with all three channels of aging. We find that non-college-educated consumers who enter the transition with decreasing fertility and increasing longevity in 2010 require a one-time transfer equivalent to 2.0 percent of GDP per capita to be indifferent between the two transitions. The corresponding transfer required to make college-educated consumers indifferent between the two transitions is 0.6 percent of GDP per capita. This shows that higher college attainment increases welfare for both college and non-college educated consumers. Moreover, the welfare gains from increasing college attainment further increase over the transition. To illustrate, we find that non-college-educated consumers who enter the transition with decreasing fertility and increasing longevity in 2100 require a one-time transfer equivalent to 160.0 percent of GDP per capita to be indifferent between the two transitions, whereas a transfer of 18.1 percent of GDP per capita is required to make college-educated consumers indifferent between the two transitions.

So far we have examined the welfare implications of increasing college attainment for unborn consumers under the veil of ignorance. Next, we study the welfare implications for the current cohort, which we refer to as the ex-post welfare implications of increasing college attainment. In particular, we compute the one-time transfer required to make a consumer of type $s$ in the transition with decreasing fertility and increasing longevity indifferent between that transition and the transition with all three channels of aging. Figure 5 plots the ex-post welfare implications by age and type of college. We find that higher college attainment increases average welfare of the current cohort but that the welfare gains are heterogeneous across both age groups and educational types. As illustrated in Figure 5, we find that 25-year-old college graduates in the transition with decreasing fertility and increasing longevity require a one-time transfer equivalent to 4.6 percent of GDP per capita to be indifferent between that transition and the transition with all three channels of aging. The corresponding transfer required to make 25-year-old non-college graduates indifferent between the two transitions is 2.8 percent of GDP per capita. The increase in average welfare due to higher college attainment is decreasing with age. This follows because older consumers are less affected by the reduction in the labor tax rate brought about by higher college attainment because of their lower labor force participation rate compared to younger consumers. Moreover, it takes time for interest rates and wage rates to adjust (see the Online Appendix for details). As a result, older consumers are less affected by the general equilibrium effects brought about by increasing college attainment. Consequently, we find that consumers aged 65 and older in the transition with decreasing fertility and increasing longevity require a one-time transfer of less than 1 percent of GDP per capita to be indifferent between the two transitions. 


\subsection{Sensitivity analysis}

We have conducted a wide range of sensitivity analyses and we find that our main results are robust. That is, the findings that higher college attainment lowers the required increase in the labor tax rate due to decreasing fertility and increasing longevity, and that the fiscal implications of higher college attainment depend critically on general equilibrium effects, are robust to alternative parameterizations of the model. We limit our discussion here to three robustness checks. First, we study the effects of adding a labor force participation cost to better match the observed labor force participation rates in the data. Then we study the effects of removing government debt in the model. Finally, we study the effects of introducing progressive income taxes in the model. In all cases, we recalibrate the model to match the same targets as described in Section 3. Table 9 summarizes the implications of introducing decreasing fertility and increasing longevity $(\mathrm{f}+\mathrm{l})$ and of introducing all three channels of aging (all) under different parameterizations of the model. We use the 2100 projection for college attainment in the model with all three channels of aging.

Labor force participation cost The benchmark model overestimates the age-specific labor force participation rates in the data. Data from the Current Population Survey show that 79 percent of 20- to 64-year-olds and 16 percent of individuals aged 65 and older participated in the labor force between 2005 and 2009. The corresponding labor force participation rates in the benchmark model are 90 and 35 percent. This is partially because the model abstracts from the fixed time costs of working and the time loss due to sickness, both of which have been shown to affect labor force participation decisions. By overestimating the number of workers who contribute by paying labor taxes, the model underestimates the labor tax burden in the economy. To address this, we add a utility cost of working in the model. All consumers who choose to participate in the labor force suffer a utility cost. We calibrate this cost to match average labor force participation rates for workers aged 20 and older between 2005 and 2009. To ensure a balanced growth path, we assume that the utility cost grows at the rate of technological progress. A comparison of the labor force participation rate in the model and the data is given in Figure 6. As illustrated in the graph, the model closely matches the observed labor force participation rates of $40+$ year-olds but continues to overestimate the labor force participation rates of younger consumers. This is partially because of the assumption that consumers enter the economy with zero assets.

Table 9 shows that the three channels of aging lead to similar changes in Social Security spending per capita, public health care spending per capita, and interest payments on government debt per capita in the model with and without labor force participation costs. Moreover, we find that the three channels of aging lead to higher effective labor per capita and higher capital per capita in both models, although the increase is higher in the benchmark model. Our results show that the increase in consumption tax revenues per capita 
is 5.4 percentage points higher in the benchmark model. Both models, however, have similar implications for capital income tax revenues per capita. Finally, we find that both models have comparable implications for the labor tax rate. In particular, increasing college attainment lowers the required increase in the labor tax rate due to decreasing fertility and increasing longevity from 13.6 to 1.6 percentage points in the benchmark model and from 13.3 to 3.5 percentage points in the model with labor force participation costs.

No government debt Recall that interest payments on government debt account for 6.8 percent of total government spending in the initial balanced growth path of the benchmark model and that the reduction in the interest rate due to the three channels of aging leads to a 62.8 percent reduction in interest payments on government debt per capita. Lower interest payments on government debt thus partially mitigate the negative fiscal implications of aging. To better understand how government debt affects the fiscal implications of aging, we next study an alternative parameterization of the model with no government debt.

The reduction in government spending caused by lower interest payments on government debt per capita lowers the required increase in the labor tax rate due to decreasing fertility and increasing longevity. Table 9 shows that the government has to increase the labor tax rate by 13.6 percentage points in the benchmark model with decreasing fertility and increasing longevity but by 14.5 percentage points in the model with no government debt. Moreover, the reduction in the labor tax rate due to increasing college attainment is larger in the benchmark model. We find that increasing college attainment lowers the required increase in the labor tax rate due to decreasing fertility and increasing longevity by 12.0 percentage points in the benchmark model and by 8.8 percentage points in the model with no government debt. The higher increase in the labor tax rate in the model with no government debt reduces incentives to work. Consequently, we find that the three channels of aging lead to an additional 3.3 percentage point increase in effective labor per capita in the benchmark model compared with the model with no government debt. Similarly, we find that the three channels of aging lead to an additional 18.3 percentage point increase in capital per capita in the benchmark model. The relatively higher increase in capital per capita compared with effective labor per capita leads to an additional 3.7 percentage point increase in the wage rate and to an additional 0.5 percentage point reduction in the interest rate in the benchmark model compared with the model with no government debt. These price effects have implications for government tax revenues. On the one hand, the higher increase in the wage rate in the benchmark model leads to a larger increase in consumption and therefore a higher increase in consumption tax revenues per capita. On the other hand, the larger reduction in the interest rate in the benchmark model has negative implications for capital income tax revenues per capita, which decline by 13.1 percent in the benchmark model when we introduce all three channels of aging but decline by 2.3 percent in the model with no government debt. 
Progressive income taxes The benchmark model allows for linear capital income taxes, linear consumption taxes, and linear labor income taxes. This subsection instead considers an alternative tax system with linear consumption taxes and progressive income taxes. In particular, we use the tax function studied by Heathcote et al. (2017):

$$
T(y)=y-\lambda y^{1-\tau}
$$

where $y=S S_{e j}+w \eta \xi_{h} \epsilon_{j e} \ell+r a$ is income, $\tau$ determines the degree of progressivity of the tax system, and $\lambda$ determines the average level of taxation in the economy. Heathcote et al. (2017) show that a value of 0.181 for $\tau$ closely matches the actual tax and transfer system in the United States. We use their value for $\tau$ and adjust $\lambda$ each period to balance the government budget.

We find that the increase in Social Security spending per capita due to the three channels of aging is comparable in the benchmark model and the model with progressive income taxes. Moreover, in both models, we find that the three channels of aging lead to lower public health care spending per capita and lower interest payments on government debt per capita, although the reductions are larger in the benchmark model. Similarly, we find that effective labor per capita and capital per capita increase in both models but that the increase is lower in the model with progressive income taxes. The increase in the wage rate and the reduction in the interest rate due to the three channels of aging is therefore higher in the benchmark model. Lastly, we find that decreasing fertility and increasing longevity increase the average income tax rate from 31.0 to 35.0 percent in the model with progressive income taxes. Introducing higher college attainment in this model allows the government to reduce the average income tax rate in the economy by 0.2 percentage points if college attainment increases to its projected value in 2100. Consequently, whereas higher college attainment lowers the required increase in the labor tax rate in the benchmark model, we find that it more than offsets the negative fiscal implications of decreasing fertility and increasing longevity in the model with progressive income taxes.

\section{Conclusion}

The old age dependency ratio will increase over the course of the 21st century because of decreasing fertility rates and increasing longevity. We have shown that increasing college attainment is another important driver of the increase in the old age dependency ratio because college graduates have higher life expectancy than noncollege graduates. Using a general equilibrium overlapping generations model with heterogeneous consumers, we have shown that the macroeconomic implications of increasing college attainment are different from those of decreasing fertility and increasing longevity. Most importantly, decreasing fertility and increasing longevity 
require the government to increase labor taxes, whereas increasing college attainment allows the government to reduce labor taxes. This follows because increasing college attainment leads to a more productive labor force, lower government spending on Medicaid and Emergency Relief, higher revenues from consumption taxation, capital income taxation, and labor income taxation, and lower interest payments on government debt per capita.

We have also studied the joint fiscal implications of the three channels of aging. In particular, we studied the fiscal implications of introducing increasing college attainment into the model with decreasing fertility and increasing longevity. We showed that decreasing fertility and increasing longevity require the government to increase the average labor tax rate from 33.5 to 47.1 percent by 2100. Adding increasing college attainment to this model lowers the required increase in the labor tax rate by 12.0 percentage points if college attainment increases to its projected value in 2100. Consequently, we have shown that all three channels of aging require the government to increase the average labor tax rate from 33.5 to 35.1 percent.

We have also shown that the fiscal implications of aging depend critically on general equilibrium effects. We have shown that the reduction in the interest rate under general equilibrium reduces capital income tax revenues per capita. Consequently, the labor tax rate required to balance the government budget is higher under general equilibrium than in a small open economy model with a constant interest rate. In particular, whereas higher college attainment lowers the required increase in the labor tax rate due to decreasing fertility and increasing longevity by 12.0 percentage points under general equilibrium, we find that the three channels of aging allow the government to reduce the labor tax rate by 6.0 percentage points in the small open economy model.

Finally, we have studied the implications for welfare by comparing the results from two demographic transitions: one where we only decrease fertility and increase longevity; and another where we introduce all three channels of aging. We have shown that higher college attainment leads to welfare gains for both current and future cohorts and that the welfare gains are increasing over time.

We think a worthwhile extension of our analysis would be to incorporate tuition costs and student debt in the model and to endogenize college attainment. Introducing student debt in the model is not simple because student loans are a form of debt that cannot be defaulted on in the United States. With idiosyncratic risk, consumers in the model might either choose to or be forced to default on student debt. This implies that student debt would have a different interest rate than other borrowing or lending in the model and that we would have to add an additional state variable for college-educated consumers (that is, their student debt). A complete analysis of educational choice would also involve benevolent parents and inter vivos bequests. We think this is a promising direction for future research. 


\section{References}

Attanasio, O., S. Kitao, and G. L. Violante (2010), "Financing Medicare: A general equilibrium analysis," in J. B. Shoven (ed.), Demography and the Economy (333-366), Chicago: University of Chicago Press.

Blundell, R., and T. MaCurdy (1999), "Labor supply: A review of alternative approaches," in O. Ashenfelter and D. Card (eds.), Handbook of Labor Economics (1559-1695), Volume 3A, Amsterdam: Elsevier.

Castañeda, A., J. Díaz-Giménez, and J.-V. Ríos-Rull (2003), "Accounting for the U.S. earnings and wealth inequality," Journal of Political Economy, 111: 818-857.

Chetty, R., A. Guren, D. Manoli, and A. Weber (2011), "Are micro and macro labor supply elasticities consistent? A review of evidence on the intensive and extensive margins," American Economic Review: Papers 85 Proceedings, 101: 471-475.

Conesa, J. C., D. Costa, P. Kamali, T. J. Kehoe, V. M. Nygaard, G. Raveendranathan, and A. Saxena (2018), "Macroeconomic effects of Medicare," Journal of the Economics of Ageing, 11: 27-40.

Conesa, J. C., and D. Krueger (1999), "Social Security reform with heterogeneous agents," Review of Economic Dynamics, 2: 757-795.

De Nardi, M., E. French, and J. B. Jones (2010), "Why do the elderly save? The role of medical expenses," Journal of Political Economy, 118: 39-75.

De Nardi, M., S. İmrohoroğlu, and T. J. Sargent (1999), "Projected U.S. demographics and Social Security," Review of Economic Dynamics, 2: 575-615.

Eckstein, Z., M. Keane, and O. Lifshitz (2019), "Career and family decisions: Cohorts born 1935-1975," Econometrica, 87: 217-253.

Heathcote, J., K. Storesletten, and G. L. Violante (2017), "Optimal tax progressivity: An analytical framework" Quarterly Journal of Economics, 132: 1693-1754.

Hubbard, R. G., J. Skinner, and S. P. Zeldes (1994), "The importance of precautionary motives in explaining individual and aggregate saving," Carnegie-Rochester Conference Series on Public Policy, 40: 59-125.

Jung, J., and C. Tran (2016), "Market inefficiency, insurance mandate and welfare: U.S. health care reform 2010," Review of Economic Dynamics, 20: 132-159.

Jung, J., C. Tran, and M. Chambers (2017), "Aging and health financing in the U.S.: A general equilibrium analysis," European Economic Review, 100: 428-462.

Keane, M. P. (2011), "Labor supply and taxes: A survey," Journal of Economic Literature, 49: 961-1075. 
Kopecky, K. A., and T. Koreshkova (2014), "The impact of medical and nursing home expenses on savings," American Economic Journal: Macroeconomics, 6: 29-72.

Kotlikoff, L. J., K. Smetters, and J. Walliser (2007), "Mitigating America's demographic dilemma by prefunding social security," Journal of Monetary Economics, 54: 247-266.

Mendoza, E. G., A. Razin, and L. L. Tesar (1994), "Effective tax rates in macroeconomics: Cross-country estimates of tax rates on factor incomes and consumption," Journal of Monetary Economics, 34: 297-323.

Palumbo, M. G. (1999), "Uncertain medical expenses and precautionary saving near the end of the life cycle," Review of Economic Studies, 66: 395-421.

Pashchenko, S., and P. Porapakkarm (2013), "Quantitative analysis of health insurance reform: Separating regulation from redistribution," Review of Economic Dynamics, 16: 383-404.

Social Security Administration (2019), "Retirement benefits," Social Security Administration, Publication No. 05-10035. 
Table 1: Parameters determined outside the model equilibrium

\begin{tabular}{|c|c|c|c|}
\hline Parameter & & Description & Value \\
\hline \multicolumn{4}{|l|}{ Life cycle } \\
\hline$J$ & Maximum life span & 100 years & 81 \\
\hline$j_{r}$ & Retirement age & 65 years & 46 \\
\hline \multicolumn{4}{|c|}{ Preferences, indivisible labor, and cost of going to college } \\
\hline$\sigma$ & Risk aversion parameter & $\mathrm{IES}=0.5$ & 3.964 \\
\hline$\ell_{p}, \ldots, \ell_{f}, \ldots, \ell_{e}$ & Indivisible labor supply grid & Hours ( $\%$ of time endow.) & $0.167, \ldots, 0.333, \ldots, 0.500$ \\
\hline$f_{e}$ & Time cost of going to college & Hours ( $\%$ of time endow.) & 0.500 \\
\hline \multicolumn{4}{|l|}{ Technology } \\
\hline$g_{z}$ & Productivity growth rate & & 0.020 \\
\hline$\alpha$ & Capital income share & & 0.360 \\
\hline$\delta$ & Capital depreciation rate & & 0.059 \\
\hline \multicolumn{4}{|c|}{ Idiosyncratic labor productivity } \\
\hline$\xi_{1}, \xi_{2}, \xi_{3}$ & Health-specific productivity & Conesa et al. (2018) & $1,1,0$ \\
\hline$\epsilon_{j e}$ & Age- and education-specific productivity & Conesa et al. (2018) & Supplementary appendix \\
\hline \multicolumn{4}{|c|}{ Health insurance } \\
\hline$\chi_{P}$ & Private insurance coinsurance rate & MEPS & 0.229 \\
\hline$\chi_{E}$ & Employer insurance coinsurance rate & MEPS & 0.229 \\
\hline$\chi_{C A R E}$ & Medicare coinsurance rate & MEPS & 0.500 \\
\hline$\chi_{C A I D}$ & Medicaid coinsurance rate & MEPS & 0.138 \\
\hline$y^{C A T}$ & Categorical income limit & Kaiser Family Foundation & 0.196 \\
\hline$y^{M N}$ & Medically needy income limit & Kaiser Family Foundation & 0.091 \\
\hline$a^{M N}$ & Medically needy asset limit & Kaiser Family Foundation & 0.041 \\
\hline \multicolumn{4}{|c|}{ Health care expenses and health transition probabilities } \\
\hline$m_{j e}$ & Health care expenses & MEPS & Supplementary appendix \\
\hline$Q_{j, e}\left(h, h^{\prime}\right)$ & Health transition probabilities & MEPS & Supplementary appendix \\
\hline \multicolumn{4}{|c|}{ Survival probabilities } \\
\hline$\psi_{j e h}$ & Age-, educ.-, and health-specific surv. prob. & MEPS & Supplementary appendix \\
\hline \multicolumn{4}{|c|}{ College attainment and 20 -year-old population growth rate } \\
\hline & Perc. of population with college degree & Census (average 2005-2009) & 0.2862 \\
\hline$g_{n, 2005}$ & Population growth rate of 20-year-olds & U.N. (average 1980-2005) & 0.0030 \\
\hline \multicolumn{4}{|l|}{ Taxes } \\
\hline$\tau_{c}$ & Consumption tax rate & OECD (average 2005-2009) & 0.047 \\
\hline$\tau_{k}$ & Capital income tax rate & OECD (average 2005-2009) & 0.321 \\
\hline
\end{tabular}


Table 2: Parameters determined jointly in equilibrium

\begin{tabular}{lllr}
\hline Parameter & Description & Target $($ year $=\mathbf{2 0 0 5}-\mathbf{2 0 0 9})$ & Value \\
\hline & & & \\
$\theta$ & Choice of units for output & GDP per capita $=1$ & 0.887 \\
$\beta$ & Discount factor & Capital to output $=3$ & 1.028 \\
$\gamma$ & Consumption share in utility & Average hours worked per employee $=0.333$ & 0.337 \\
$b_{c}$ & SS college replacement rate & Average SS benefits college $\approx \$ 13,800$ & 0.510 \\
$b_{n c}$ & SS non-college replacement rate & Average SS benefits non-college $\approx 11,500$ & 0.417 \\
$\underline{c}$ & Consumption floor & Average food stamps $\approx \$ 1,200$ & 0.026 \\
$\kappa$ & Utility cost of Medicaid & Medicaid exp. to total health exp. $=0.155$ & 0.166 \\
$g_{c}$ & Government consumption per capita & Government consumption to output $=0.156$ & 0.156 \\
$D$ & Government debt & Government debt to output $=0.547$ & 30.199 \\
& Eligible for employer insurance & Working-age share with employer ins. $=0.480$ & 0.500 \\
& Scale for health care costs & Health care expenditure to GDP $=0.152$ & 1.461 \\
$\sigma_{\eta}$ & Variance & Labor earnings Gini $=0.630$ & \\
$\eta_{t o p}$ & Productivity at the top & Labor earnings top 1 percent $=0.148$ & 2.045 \\
$\pi_{t o p}$ & Probability at the top & Labor earnings top 10 percent $=0.435$ & 0.940 \\
$\rho_{n}$ & Persistence & 2-year persistence: Bottom 80 percent $=0.941$ & 0.904 \\
$\rho_{t o p}$ & Persistence at the top & 2-year persistence: Top 1 percent $=0.580$ & 0.807 \\
\hline
\end{tabular}

Figure 1: Micro Frisch elasticity

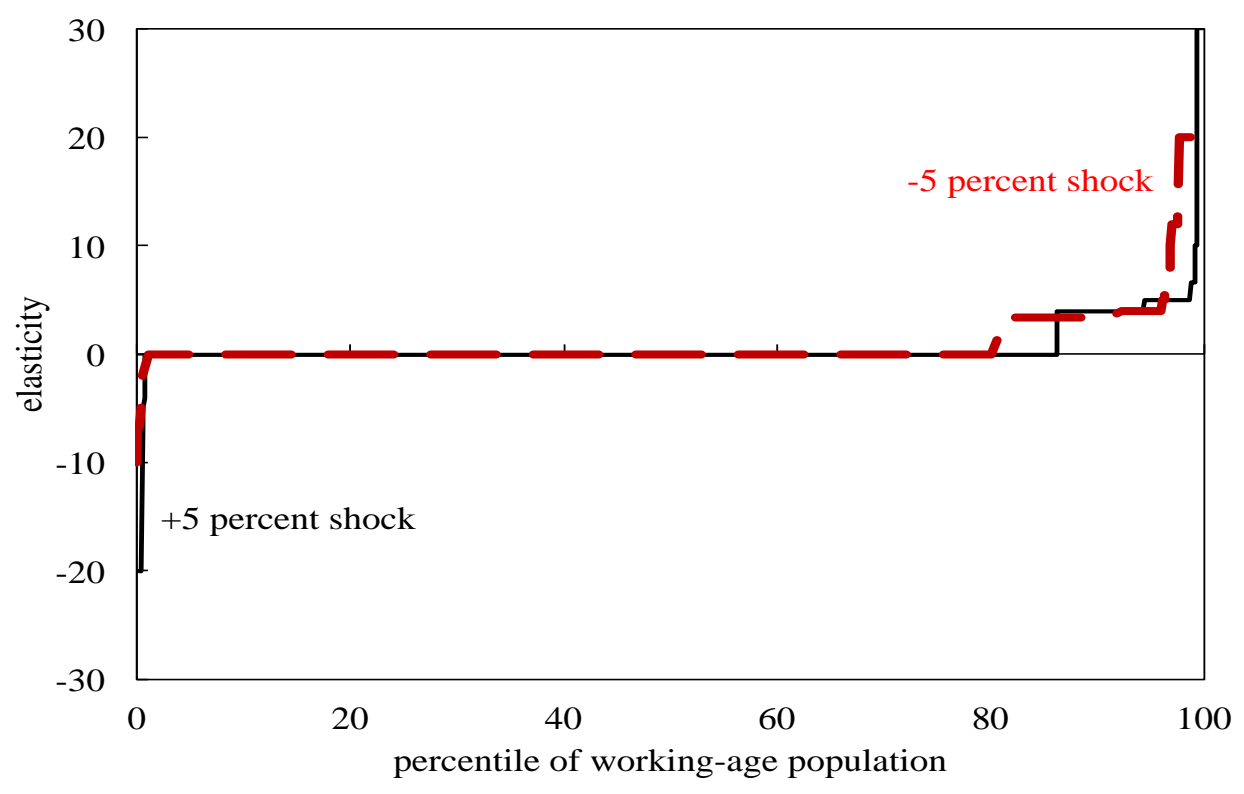


Table 3: Values in $\mathbf{2 0 0 5}$ and projections for $\mathbf{2 1 0 0}$ for college attainment and fertility

\begin{tabular}{lrr}
\hline Parameter & $\mathbf{2 0 0 5}$ & $\mathbf{2 1 0 0}$ (projection) \\
\hline & & \\
Fraction of college graduates $25+$ & 0.2862 & 0.7048 \\
Annual population growth rate of 20-year-olds: $g_{n}$ & 0.0030 & -0.0005
\end{tabular}

Figure 2: College attainment
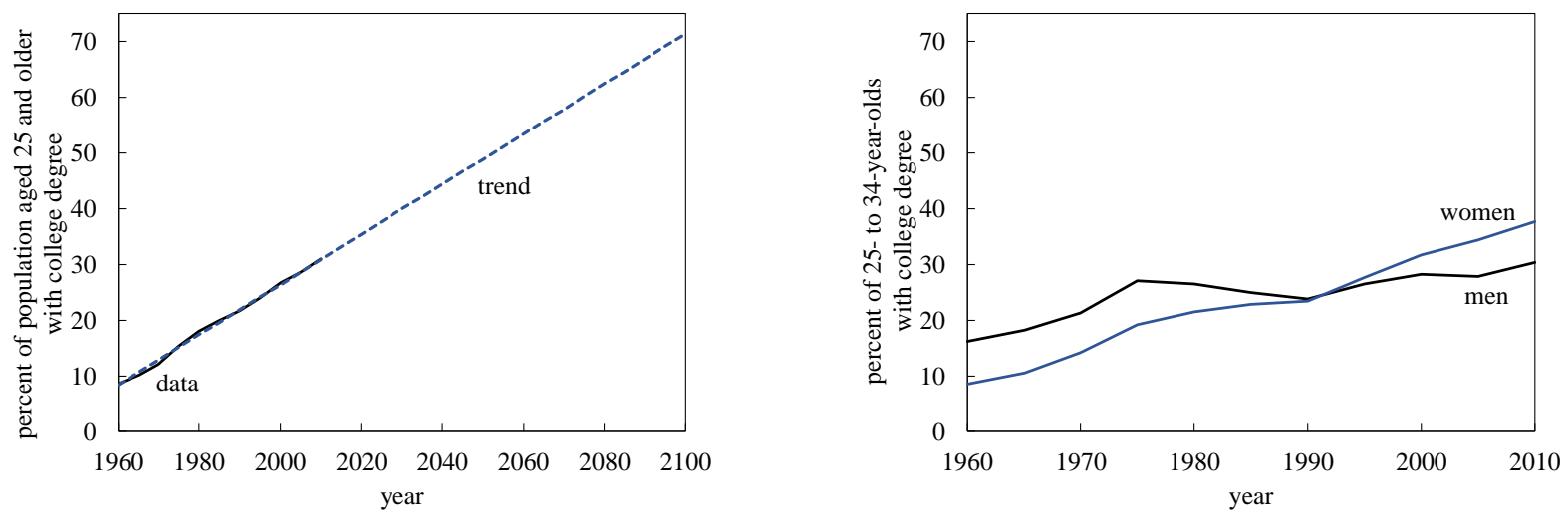

Figure 3: Survival probabilities by age, medical spending, and education in 2005 (solid) and 2100 (dashed)
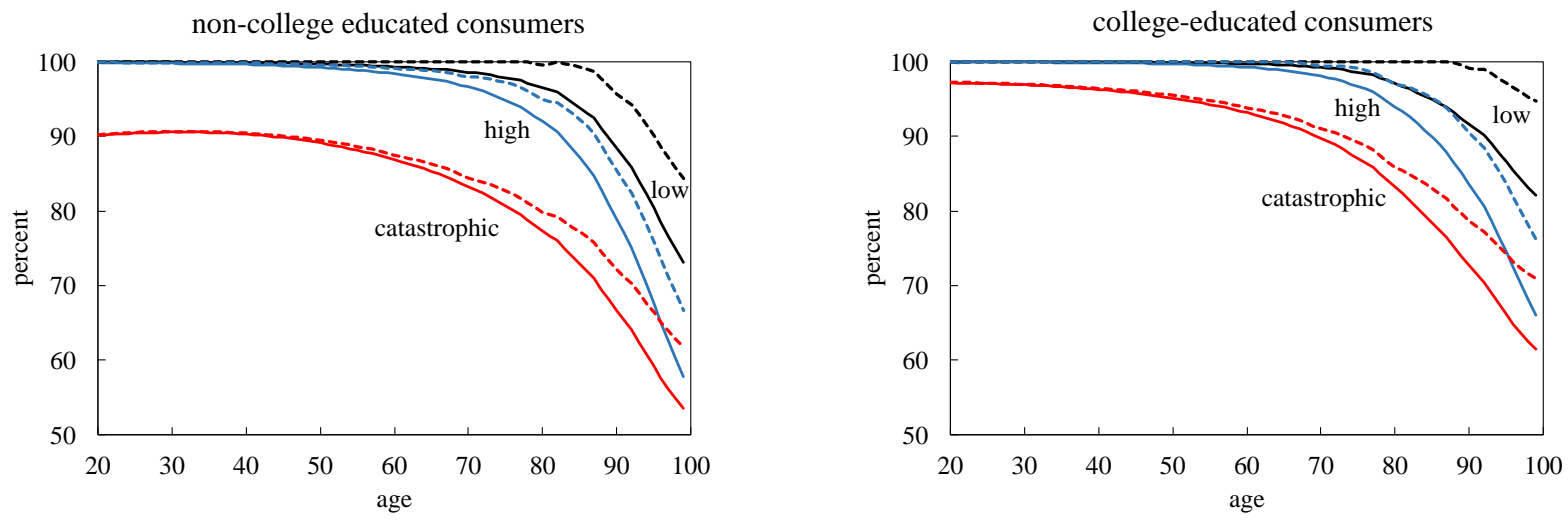
Table 4: Individual implications: old age dependency ratio, labor tax rate, capital, labor supply, and output

\begin{tabular}{|c|c|c|c|}
\hline Percent of 2100 projection & 0 & 50 & 100 \\
\hline \multicolumn{4}{|c|}{ Ratio population $65+/(20-64)$ (percent) } \\
\hline Increased college attainment & 35.3 & 37.1 & 38.8 \\
\hline Decreased fertility & 35.3 & 37.5 & 39.9 \\
\hline Increased longevity & 35.3 & 42.1 & 51.5 \\
\hline \multicolumn{4}{|l|}{ Labor tax rate (percent) } \\
\hline Increased college attainment & 33.5 & 29.2 & 26.4 \\
\hline Decreased fertility & 33.5 & 35.2 & 37.1 \\
\hline Increased longevity & 33.5 & 35.9 & 39.6 \\
\hline \multicolumn{4}{|c|}{ Capital, labor supply, and output } \\
\hline Increased college attainment & 100.0 & 119.9 & 138.1 \\
\hline Decreased fertility & 100.0 & 98.3 & 95.9 \\
\hline Increased longevity & 100.0 & 104.8 & 108.4 \\
\hline \multicolumn{4}{|c|}{ Effective labor per capita (index, $2005=100$ ) } \\
\hline Increased college attainment & 100.0 & 108.0 & 115.4 \\
\hline Decreased fertility & 100.0 & 98.7 & 97.1 \\
\hline Increased longevity & 100.0 & 98.5 & 96.4 \\
\hline \multicolumn{4}{|c|}{ Hours worked per capita (index, $2005=100$ ) } \\
\hline Increased college attainment & 100.0 & 101.3 & 101.8 \\
\hline Decreased fertility & 100.0 & 97.9 & 95.4 \\
\hline Increased longevity & 100.0 & 98.3 & 95.6 \\
\hline \multicolumn{4}{|c|}{ Labor force participation rate $20-64$ (percent) } \\
\hline Increased college attainment & 90.3 & 91.8 & 92.7 \\
\hline Decreased fertility & 90.3 & 89.7 & 88.8 \\
\hline Increased longevity & 90.3 & 90.9 & 90.8 \\
\hline \multicolumn{4}{|c|}{ Labor force participation rate $65+$ (percent) } \\
\hline Increased college attainment & 34.9 & 37.4 & 39.4 \\
\hline Decreased fertility & 34.9 & 34.1 & 33.3 \\
\hline Increased longevity & 34.9 & 33.3 & 30.8 \\
\hline \multicolumn{4}{|c|}{ Output per capita (index, $2005=100)$} \\
\hline Increased college attainment & 100.0 & 112.1 & 123.1 \\
\hline Decreased fertility & 100.0 & 98.5 & 96.7 \\
\hline Increased longevity & 100.0 & 100.7 & 100.6 \\
\hline
\end{tabular}


Table 5: Individual implications: health care expenditure distribution by provider (percent)

\begin{tabular}{lrrr}
\hline Percent of 2100 projection & 0 & 50 & 100 \\
\hline & & & \\
Increased college attainment & & & \\
Private insurance & 15.2 & 16.8 & 18.2 \\
Employer insurance & 18.6 & 18.2 & 17.8 \\
Medicare & 25.0 & 25.7 & 26.4 \\
Medicaid & 15.4 & 13.0 & 11.2 \\
Out-of-pocket & 23.8 & 24.5 & 24.8 \\
Emergency relief & 1.9 & 1.7 & 1.6 \\
& & & \\
Decreased fertility & & & \\
Private insurance & 15.2 & 14.9 & 14.6 \\
Employer insurance & 18.6 & 17.9 & 17.2 \\
Medicare & 25.0 & 25.7 & 26.4 \\
Medicaid & 15.4 & 16.0 & 16.7 \\
Out-of-pocket & 23.8 & 23.3 & 22.7 \\
Emergency relief & 1.9 & 2.1 & 2.3 \\
& & & \\
Increased longevity & & & \\
Private insurance & 15.2 & 15.1 & 14.5 \\
Employer insurance & 18.6 & 16.5 & 14.0 \\
Medicare & 25.0 & 27.7 & 30.7 \\
Medicaid & 15.4 & 15.5 & 16.3 \\
Out-of-pocket & 23.8 & 23.3 & 22.4 \\
Emergency relief & 1.9 & 1.9 & 2.1 \\
& & & \\
\hline
\end{tabular}


Table 6: Individual implications: prices, government expenditures, and government revenues

\begin{tabular}{|c|c|c|c|}
\hline Percent of 2100 projection & 0 & 50 & 100 \\
\hline \multicolumn{4}{|l|}{ Prices } \\
\hline \multicolumn{4}{|l|}{ Wage rate (index, $2005=100)$} \\
\hline Increased college attainment & 100.0 & 103.8 & 106.7 \\
\hline Decreased fertility & 100.0 & 99.9 & 99.5 \\
\hline Increased longevity & 100.0 & 102.3 & 104.3 \\
\hline \multicolumn{4}{|l|}{ Interest rate (percent) } \\
\hline Increased college attainment & 6.1 & 5.3 & 4.8 \\
\hline Decreased fertility & 6.1 & 6.1 & 6.2 \\
\hline Increased longevity & 6.1 & 5.6 & 5.2 \\
\hline \multicolumn{4}{|c|}{ Government expenditures } \\
\hline \multicolumn{4}{|c|}{ Public health care spending per capita (index, $2005=100$ ) } \\
\hline Increased college attainment & 100.0 & 96.0 & 93.7 \\
\hline Decreased fertility & 100.0 & 104.8 & 110.3 \\
\hline Increased longevity & 100.0 & 113.6 & 132.0 \\
\hline \multicolumn{4}{|c|}{ Interest payments on government debt per capita (index, $2005=100)$} \\
\hline Increased college attainment & 100.0 & 78.0 & 63.1 \\
\hline Decreased fertility & 100.0 & 100.0 & 100.5 \\
\hline Increased longevity & 100.0 & 82.4 & 67.1 \\
\hline \multicolumn{4}{|c|}{ Social Security spending per capita (index, $2005=100)$} \\
\hline Increased college attainment & 100.0 & 112.2 & 123.5 \\
\hline Decreased fertility & 100.0 & 104.1 & 108.1 \\
\hline Increased longevity & 100.0 & 112.9 & 128.1 \\
\hline \multicolumn{4}{|l|}{ Government revenues } \\
\hline \multicolumn{4}{|c|}{ Consumption tax revenues per capita (index, $2005=100$ ) } \\
\hline Increased college attainment & 100.0 & 115.7 & 129.7 \\
\hline Decreased fertility & 100.0 & 98.1 & 95.6 \\
\hline Increased longevity & 100.0 & 96.4 & 90.5 \\
\hline \multicolumn{4}{|c|}{ Capital income tax revenues per capita $($ index, $2005=100)$} \\
\hline Increased college attainment & 100.0 & 101.7 & 103.6 \\
\hline Decreased fertility & 100.0 & 98.2 & 96.4 \\
\hline Increased longevity & 100.0 & 95.2 & 90.1 \\
\hline
\end{tabular}


Table 7: Joint implications of increased college attainment, decreased fertility, and increased longevity

\begin{tabular}{|c|c|c|c|}
\hline $\begin{array}{l}\text { Percent of projected increase in college attainment } \\
\text { (fertility and longevity equal to their } 2100 \text { projections) }\end{array}$ & 0 & 50 & 100 \\
\hline \multicolumn{4}{|l|}{ Population } \\
\hline Ratio population $65+/(20-64)$ (percent) & 58.7 & 61.4 & 64.0 \\
\hline \multicolumn{4}{|l|}{ Prices } \\
\hline Wage rate $($ index, $2005=100)$ & 101.2 & 108.0 & 112.4 \\
\hline Interest rate (percent) & 5.9 & 4.6 & 3.9 \\
\hline \multicolumn{4}{|l|}{ Government expenditures } \\
\hline Social Security spending per capita (index, $2005=100$ ) & 134.2 & 153.4 & 169.2 \\
\hline Public health care spending per capita (index, $2005=100$ ) & 150.0 & 141.1 & 135.4 \\
\hline Interest payments on government debt per capita (index, $2005=100)$ & 79.3 & 52.1 & 37.2 \\
\hline \multicolumn{4}{|l|}{ Taxation } \\
\hline Labor tax rate (percent) & 47.1 & 39.5 & 35.1 \\
\hline Capital income tax revenues per capita (index, $2005=100$ ) & 87.4 & 87.0 & 86.9 \\
\hline Consumption tax revenues per capita (index, $2005=100)$ & 79.4 & 98.8 & 114.4 \\
\hline \multicolumn{4}{|l|}{ Capital, labor supply, and output } \\
\hline Capital per capita (index, $2005=100)$ & 93.9 & 123.8 & 149.2 \\
\hline Effective labor per capita (index, $2005=100$ ) & 90.9 & 100.0 & 108.0 \\
\hline Hours worked per capita (index, $2005=100$ ) & 87.9 & 91.8 & 93.9 \\
\hline Labor force participation rate $20-64$ (percent) & 88.3 & 91.2 & 92.8 \\
\hline Labor force participation rate $65+$ (percent) & 26.8 & 29.9 & 32.3 \\
\hline Output per capita $($ index, $2005=100)$ & 92.0 & 108.0 & 121.3 \\
\hline
\end{tabular}

Table 8: Tax implications of increased college attainment, decreased fertility, and increased longevity: general equilibrium versus small open economy

\begin{tabular}{|c|c|c|c|c|c|c|}
\hline \multirow[b]{2}{*}{$\begin{array}{l}\text { Percent of projected increase in college attainment } \\
\text { (fertility and longevity equal to their } 2100 \text { projections) }\end{array}$} & \multicolumn{3}{|c|}{ General equilibrium } & \multicolumn{3}{|c|}{ Small open economy } \\
\hline & 0 & 50 & 100 & 0 & 50 & 100 \\
\hline Labor tax rate (p.p., $2005=0$ ) & 13.6 & 6.0 & 1.6 & 13.7 & 1.8 & -6.0 \\
\hline Consumption tax revenues per capita (percent, $2005=0$ ) & -20.6 & -1.2 & 14.4 & -20.8 & 6.9 & 30.2 \\
\hline Capital income tax revenues per capita (percent, $2005=0$ ) & -12.6 & -13.0 & -13.1 & -7.6 & 45.2 & 89.4 \\
\hline
\end{tabular}


Table 9: Robustness

\begin{tabular}{|c|c|c|c|c|c|c|c|c|}
\hline & \multicolumn{2}{|c|}{ Benchmark } & \multicolumn{2}{|c|}{ Lab. part. cost } & \multicolumn{2}{|c|}{ No gov. debt } & \multicolumn{2}{|c|}{ Prog. inc. tax } \\
\hline & $\mathrm{f}+\mathrm{l}$ & all & $\mathrm{f}+\mathrm{l}$ & all & $\mathrm{f}+\mathrm{l}$ & all & $\mathrm{f}+\mathrm{l}$ & all \\
\hline \multicolumn{9}{|l|}{ Variable (percent, $2005=0$ ) } \\
\hline Social Security exp. per capita & 34.2 & 69.2 & 34.6 & 67.6 & 31.1 & 60.0 & 43.7 & 72.8 \\
\hline Public health care exp. per capita & 50.0 & 35.4 & 51.7 & 41.5 & 51.3 & 40.7 & 40.0 & 36.2 \\
\hline Int. pay on gov. debt per capita & -20.7 & -62.8 & -22.3 & -59.4 & $\mathrm{n} / \mathrm{a}$ & $\mathrm{n} / \mathrm{a}$ & -44.8 & -67.8 \\
\hline Effective labor per capita & -9.1 & 8.0 & -8.9 & 5.7 & -9.4 & 4.4 & -2.9 & 9.7 \\
\hline Capital per capita & -6.1 & 49.2 & -4.9 & 42.1 & -10.3 & 26.7 & 18.4 & 58.1 \\
\hline Wage rate & 1.2 & 12.4 & 1.5 & 11.2 & -0.3 & 7.2 & 7.4 & 14.1 \\
\hline Cons. tax revenues per capita & -20.6 & 14.4 & -19.8 & 9.8 & -22.2 & 5.1 & -5.5 & 18.4 \\
\hline Cap. inc. tax revenues per capita & -12.6 & -13.1 & -12.8 & -12.8 & -9.6 & -2.3 & $\mathrm{n} / \mathrm{a}$ & $\mathrm{n} / \mathrm{a}$ \\
\hline \multicolumn{9}{|l|}{ Variable (p.p., $2005=0$ ) } \\
\hline Interest rate & -0.2 & -2.2 & -0.3 & -2.1 & 0.1 & -1.4 & -1.4 & -2.5 \\
\hline Labor tax rate & 13.6 & 1.6 & 13.3 & 3.5 & 14.5 & 5.7 & $\mathrm{n} / \mathrm{a}$ & $\mathrm{n} / \mathrm{a}$ \\
\hline Average income tax rate & $\mathrm{n} / \mathrm{a}$ & $\mathrm{n} / \mathrm{a}$ & $\mathrm{n} / \mathrm{a}$ & $\mathrm{n} / \mathrm{a}$ & $\mathrm{n} / \mathrm{a}$ & $\mathrm{n} / \mathrm{a}$ & 4.0 & -0.2 \\
\hline
\end{tabular}

Figure 4: Ex-ante welfare implications by type of college for consumers who enter the economy in year $t$ of the transition: one-time transfer required to make the consumer who enters the transition with decreasing fertility and increasing longevity indifferent between entering that transition and entering the transition with all three channels of aging

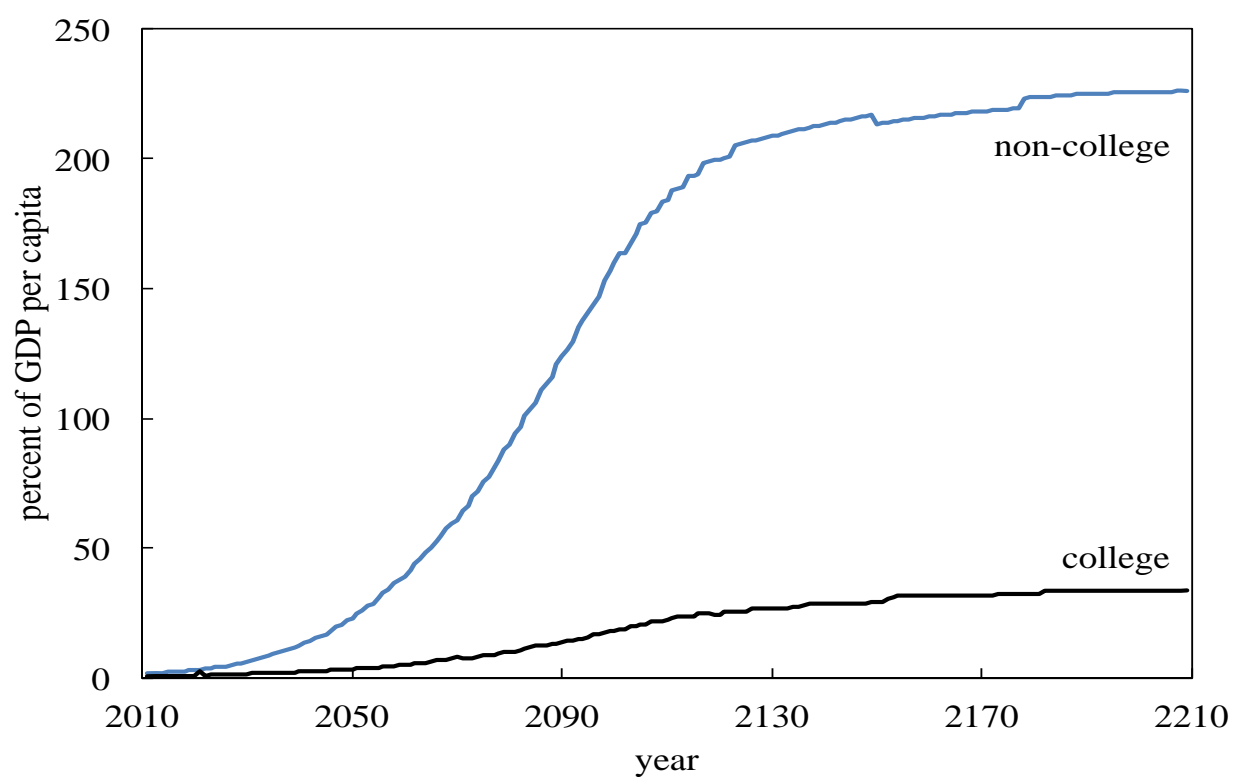


Figure 5: Ex-post welfare implications by age and type of college: one-time transfer required to make the consumer in the transition with decreasing fertility and increasing longevity indifferent between that transition and the transition with all three channels of aging

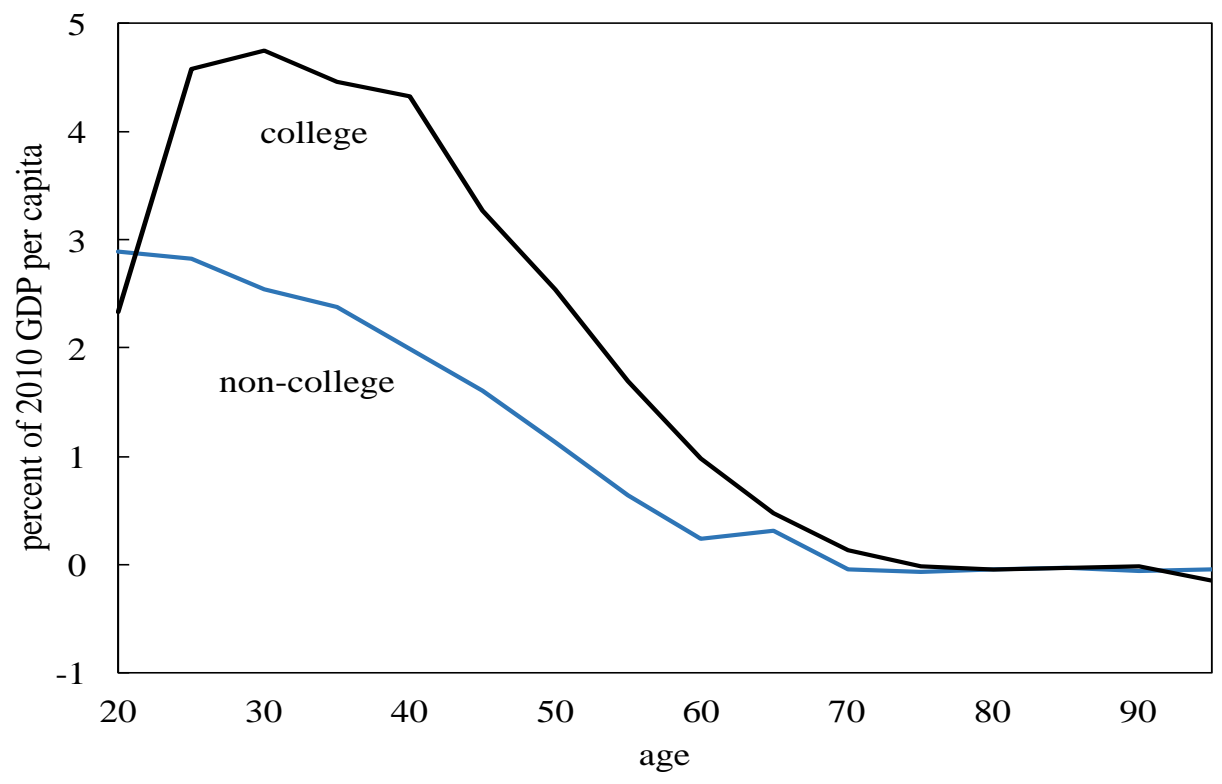

Figure 6: Robustness: model with labor force participation cost

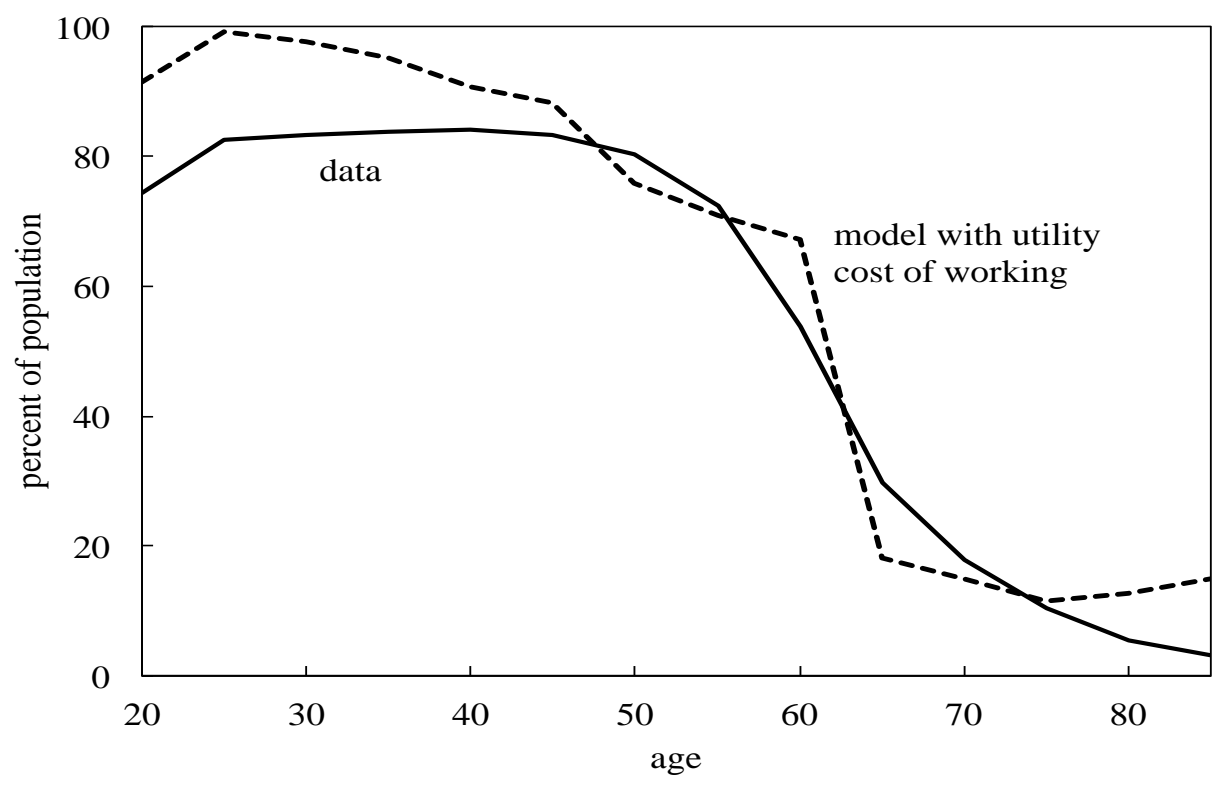

